Haro $P$, Ollero $P$, Trippe F. Technoeconomic assessment of potential processes for bio-Ethylene production. Fuel Process Technol. 2013;114:35-48. DOI: 10.1016/j.fuproc.2013.03.024

\title{
Technoeconomic assessment of potential processes for bio-Ethylene production
}

\begin{abstract}
The use of biomass in the production of plastics can contribute to the depletion of greenhouse gas (GHG) emissions and secondarily to partially fulfill the growing demand for plastics expected in the near future. The aim of

this study is to assess the production of ethylene, one of the most important commodities in the petrochemical industry, via the dehydration of bioethanol and the conversion of bio-dimethyl ether (bioDME) into olefins. Four case studies have been developed taking into account the different origins of bioethanol, and one for the conversion of bio-DME. The assessment includes current and promising processes for the production of bioethanol, i.e., 1st generation and 2nd generation bioethanol. The latter comprises biochemical processing (enzymatic hydrolysis), thermochemical processing (both direct and indirect syntheses from syngas) and hybrid processing (fermentation of syngas) of biomass. The results show that two of the considered case studies (Brazilian ethanol and ethanol via indirect synthesis from syngas) enable the cost-competitive production of ethylene at current market prices. If BECCS (Bioenergy with Carbon Capture and Storage) is taken into account for the case studies, the results would be substantially enhanced and all cases, except for the case of bioethanol from biochemical processing, would be profitable.
\end{abstract}

Keywords: Ethylene; Biomass; 1st generation bioethanol; 2nd generation bioethanol; Thermochemical processing; Technoeconomic assessment

\section{Introduction}

The production of plastics from a renewable feedstock is of great interest nowadays. The use of biomass and carbon-based waste in the production of plastics can contribute to the depletion of greenhouse gas (GHG) emissions and secondarily to partially fulfill the growing demand for plastics expected in the near future. There are several renewable feedstocks for plastic production [1], but only a limited number of petrochemical commodities could be produced from biomass using commercial or potential commercial technologies. These commodities are ethylene, propylene and BTX (benzene, toluene and xylenes) [1], which can be easily introduced in current petrochemical facilities. However, regarding both the plastic market and processing of biomass, bio-ethylene seems a reasonable medium-term target. Two reasons support this position: first, ethylene is by far the largest-volume commodity of the three mentioned above; and second, it can be produced by available or demonstrated technologies, such as the dehydration of ethanol or methanol(DME)-to-olefins [2]. Currently, the main use of ethylene is the production of plastics (via polyethylene or vinyl acetate) [2]. 


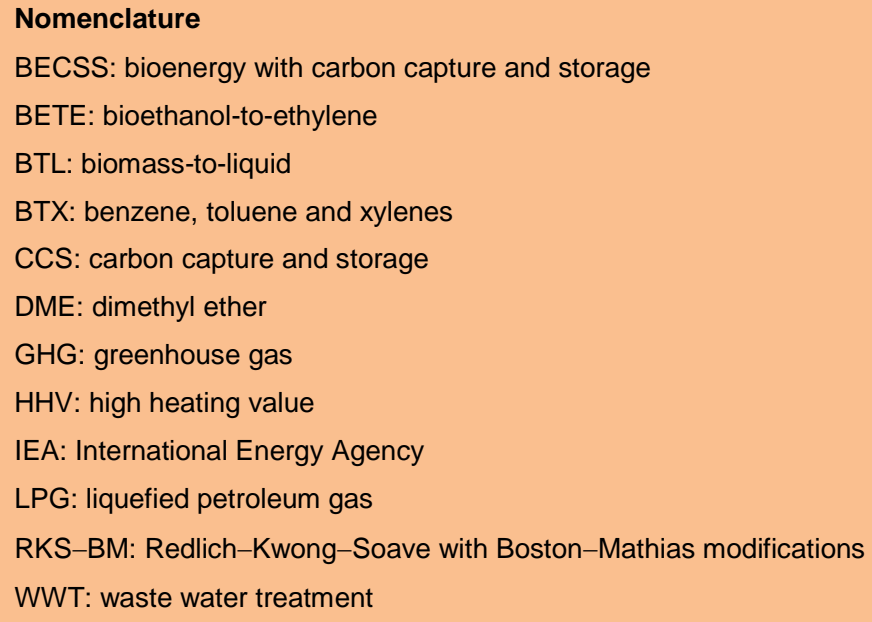

The price of ethylene is being highly dependent on the price of crude oil (see Figure 1), since half the price of ethylene is due to the feedstock (crude oil) cost [2]. Hence, the production costs of plastics, which in general use petrochemical commodities like ethylene as source, are related to the evolution of crude oil price and therefore suffer from its volatility. The introduction of biomass as a secondary or alternative feedstock would have two positive effects from an economic point of view. On the one hand, it would reduce the dependence on crude oil prices, whose evolution has fluctuated dramatically in recent years. On the other hand, it would improve industrial development in regions without natural fossil sources, but with a relatively high capacity for biomass production.

From a sustainable point of view, the potential of GHG reductions inherent in the use of biomass as a renewable carbon feedstock can be enhanced by using carbon capture and storage (CCS). This option has been recently proposed by the International Energy Agency under the BECCS (Bioenergy with Carbon Capture and Storage) concept [3]. The storage of $\mathrm{CO}_{2}$ with a renewable or green origin allows for the possibility of selling the amount of $\mathrm{CO}_{2}$ sequestrated via $\mathrm{CO}_{2}$ credits (emissions trading).

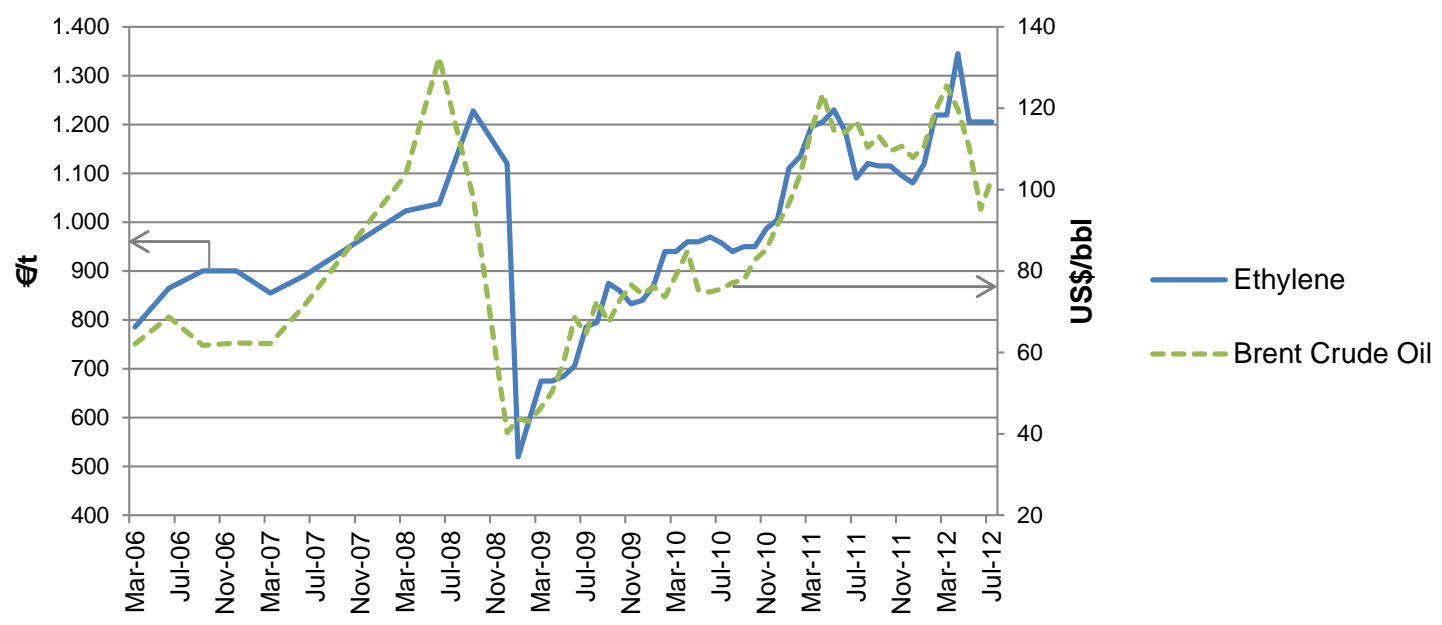

Figure 1. Ethylene contract bulk price and Brent Crude Oil price evolution from 2006 to 2012 (data taken from [4, 5]). 
The aim of this work is to study the technical and economic feasibility of different alternatives to produce bio-ethylene from biomass and to assess the possibility of extra revenues with the integration of BECCS into the processes. To date there is no published work in the literature focused on the study of bio-ethylene production and the comparison of different alternatives. Another contribution of this study is the consideration of BECCS and the possibility of extra revenues from $\mathrm{CO}_{2}$ emissions trading.

The considered alternatives for the production of bio-ethylene are shown in Table 1 and Figure 2 , and represent the current most promising routes for ethylene production from biomass. In the first set of alternatives, ethanol is the selected platform chemical for the production of ethylene (via dehydration). As ethanol can be produced from biomass by using different processes, the most representative and innovative have been included, i.e. $1^{\text {st }}$ generation bioethanol, $2^{\text {nd }}$ generation bioethanol via enzymatic hydrolysis and syngas fermentation, and $2^{\text {nd }}$ generation bioethanol via thermochemical processing. In the case of bioethanol via thermochemical processing, both the conventional syngas processing (direct route) [6] and also an innovative process recently assessed (indirect route) with promising results [7] are included. In the second set, ethylene is produced along with other olefins, mainly propylene, using DME as the platform chemical. In this process, DME is catalytically converted into hydrocarbons and it has been recently evaluated in a previous study [8].

\section{Description of the case studies}

This section provides an outline of the five case studies (see Table 1 and Figure 2), including a summary of the technology involved, process design and system boundaries for the modeling. The section is divided into two blocks accounting for alternatives using ethanol as a platform chemical and that using DME.

\subsection{Case studies involving ethanol dehydration (case studies 1-4)}

In case studies 1-4 the ethanol input for the dehydration plant is assumed to be commercial fuel grade or anhydrous ethanol. Hence, ethanol processing is the same regardless of the considered case study. For case studies 1 and 2, the plant capacity is not restricted and they are assessed for a range of plant capacities. For case studies 3 and 4 the production of ethylene is assumed to be integrated with ethanol synthesis using the process designs of the previous studies. Hence, the plant capacity in these cases is fixed. Possible alternatives for the modeling of case studies 1-4 are given in section 5.1.

\subsubsection{Case study 1: $1^{\text {st }}$ generation ethanol}

Despite the controversy surrounding the use of food-competitive feedstock, there is a great interest in the valorization of $1^{\text {st }}$ generation ethanol to high-value products. Production of ethylene was one of the first examples, e.g. the BETE (BioEthanol-To-Ethylene) process in the 1980s [12]. The relatively low-cost of $1^{\text {st }}$ generation ethanol in Brazil [9], along with the 
increasing price of crude oil, triggered the interest in the use of ethanol as a platform chemical $[2,13]$.

Despite $1^{\text {st }}$ generation ethanol representing an appealing option for ethylene production, the optimal capacity of the dehydration plant is still uncertain. Typical sizes of new ethanol plants are about 300-500 ML/year [9], whereas the average size of an ethanol plant in Brazil is about $50 \mathrm{ML} / y e a r$ [2]. This wide range of plant capacities leads to an equivalent range of ethylene production capacities if a one-to-one strategy is followed, i.e. the dehydration plant is fed with the production of a single ethanol plant. However, Braskem S.A. has recently put a combined dehydration-polymerization plant into operation with a capacity of 200 tonnes/year of polyethylene and ethanol consumption of $462 \mathrm{ML} / y e a r$ [14]. The size of Braskem's plant suggests that the one-to-one strategy is inappropriate. The selected capacities used in this assessment range from 150 to $500 \mathrm{ML} /$ year (118-395 tonnes/year) of ethanol. In this study, we consider the most relevant sources for commercial ethanol, i.e. EU, USA and Brazil.

Table 1. Summary of studied cases for ethylene production from biomass.

\begin{tabular}{|c|c|c|c|c|}
\hline $\begin{array}{l}\text { Case } \\
\text { study }\end{array}$ & Technology & Platform chemical & Status & Reference \\
\hline 1 & & $1^{\text {st }}$ generation ethanol & Already commercial & $\begin{array}{c}\text { Comercial } \\
\text { bioethanol from } \\
\text { EU, USA and } \\
\text { Brazil [9] }\end{array}$ \\
\hline 2 & Dehydration & $\begin{array}{l}2^{\text {nd }} \text { generation biochemical } \\
\text { ethanol (enzymatic hydrolysis) \& } \\
\text { ethanol via syngas fermentation }\end{array}$ & $\begin{array}{l}\text { Close to commercial } \\
\text { introduction }\end{array}$ & $\begin{array}{l}\text { Kazi et al. [10] } \\
\text { Fornell et al. [11] }\end{array}$ \\
\hline 3 & & $\begin{array}{l}2^{\text {nd }} \text { generation ethanol } \\
\text { (thermochemical, direct route) }\end{array}$ & $\begin{array}{l}\text { In advanced stage of } \\
\text { development }\end{array}$ & Villanueva et al. [6] \\
\hline 4 & & $\begin{array}{l}2^{\text {nd }} \text { generation ethanol } \\
\text { (thermochemical, indirect route) }\end{array}$ & $\begin{array}{c}\text { In a first stage of } \\
\text { development }\end{array}$ & Haro et al. [7] \\
\hline 5 & MTO & DME & $\begin{array}{l}\text { Close to commercial } \\
\text { introduction or already } \\
\text { commercial }\end{array}$ & Haro et al. [8] \\
\hline
\end{tabular}


CASE STUDY 1

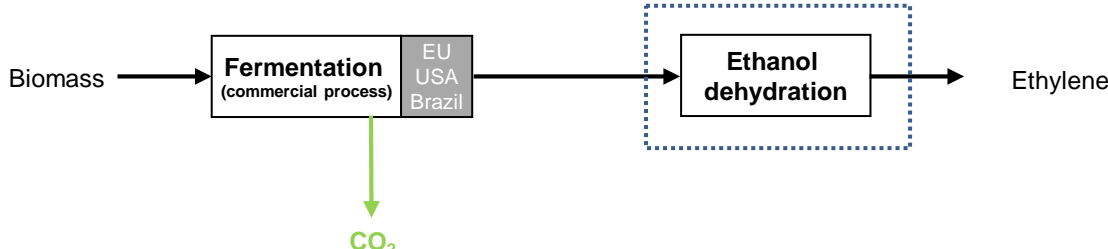

CASE STUDY 2 Biomass

CASE STUDY 3

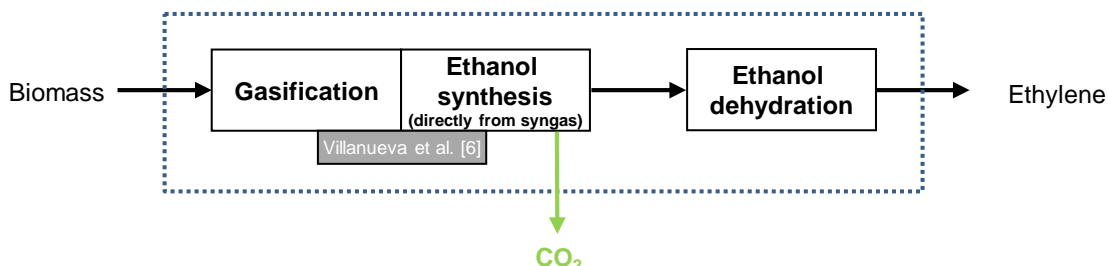

CASE STUDY 4

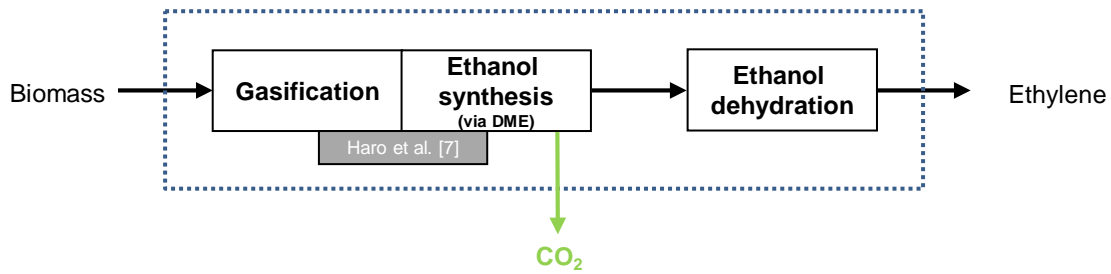

CASE STUDY 5

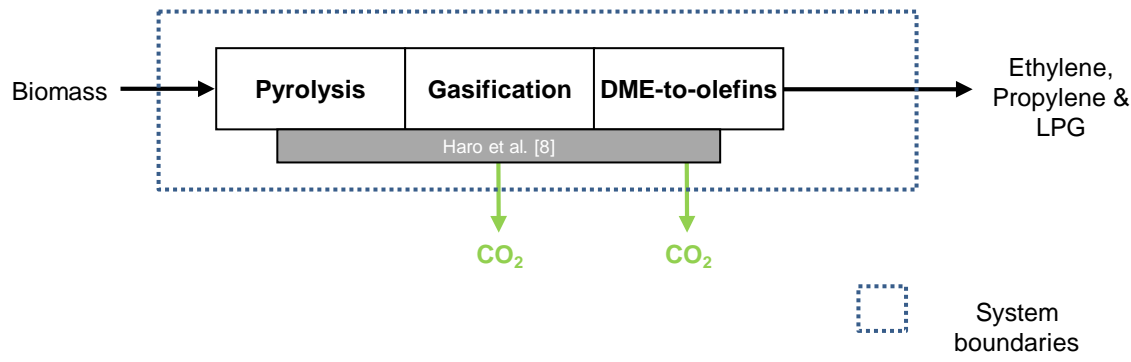

Figure 2. Outline of selected case studies and system boundaries used in this assessment. 
2.1.2. Case study $2: 2^{\text {nd }}$ generation ethanol via enzymatic hydrolysis and via syngas fermentation

Although $2^{\text {nd }}$ generation ethanol is in an advanced stage of development, there are no commercial plants in operation, so the impact on the bioethanol commercial trading price is unknown. In this study, the only estimation of prices (production cost) has been collected from literature. Nonetheless, $2^{\text {nd }}$ generation ethanol needs to be included in this assessment as it represents the most likely short-term alternative for current bioethanol production. Three alternatives are in development within $2^{\text {nd }}$ generation processes: biochemical processing (via enzymatic hydrolysis), bio-thermochemical processing (via syngas fermentation) and thermochemical processing (discussed in case studies 3 and 4). Advantages and detailed discussions on current research for $2^{\text {nd }}$ generation bioethanol, e.g. projects, pilot plants and techno-economic assessments, are given in [15-24]. The fermentation of biomass-derived syngas into ethanol is an extremely interesting alternative to conventional production processes and it is or has been in development by some companies, e.g. Coskata and LanzaTech. In spite of the interest in syngas fermentation, there is a lack of public information on the resulting ethanol price.

The plant size for a dehydration plant based on $2^{\text {nd }}$ generation ethanol is subject to more uncertainties than in case study 1 (using current bioethanol). If a scenario of complete introduction of $2^{\text {nd }}$ generation processes is selected, the ethanol production capacity of $2^{\text {nd }}$ generation processes could be twice or three times greater than the largest ethanol plants (assumption by the authors). Therefore, the selected capacities in the assessment range from 300 to $1000 \mathrm{ML} / \mathrm{year}$ (236-790 tonnes/year) of ethanol.

In order to perform this technoeconomic assessment two previous assessments of $2^{\text {nd }}$ generation ethanol via enzymatic hydrolysis have been selected as references, i.e. from the Chalmers University of Technology [11] and from the National Renewable Energy Laboratory (NREL) [10]. For the assessment of $2^{\text {nd }}$ generation ethanol via syngas fermentation, we have assumed an ethanol price according to the latest public information from Coskata Inc. [25]. However, recent news from Coskata says that they have withdrawn their plans to use biomass and they are currently focusing on natural gas [26].

2.1.3. Case study 3: $2^{\text {nd }}$ generation ethanol via thermochemical processing (direct route)

The production of bioethanol via thermochemical biomass processing involves the gasification of biomass and further conversion of syngas into ethanol. This conversion can be conducted directly, i.e. in a single catalytic reaction step, or indirectly. The direct conversion of syngas into ethanol and higher alcohols has been of great interest in the field of biomass-to-liquids (BTL) research [6, 27-35]. 
In this study, the technoeconomic assessment of Villanueva et al. [6] has been selected as a reference. The plant capacity is 2140 dry tonnes/day of wood chip $\left(500 \mathrm{MW}_{\mathrm{th}}\right)$. The production of ethanol and higher alcohols is carried out via pyrolysis and entrained flow gasification and subsequent synthesis using a Rh- or a $\mathrm{MoS}_{2}$-based catalyst. The bases for the conversion of syngas into ethanol and higher alcohols are summarized in Table 2. Figure 3 shows the flowchart of the process. In this study, only the alternative using $\mathrm{MoS}_{2}$-based catalyst (a proprietary catalyst) is analyzed [6].

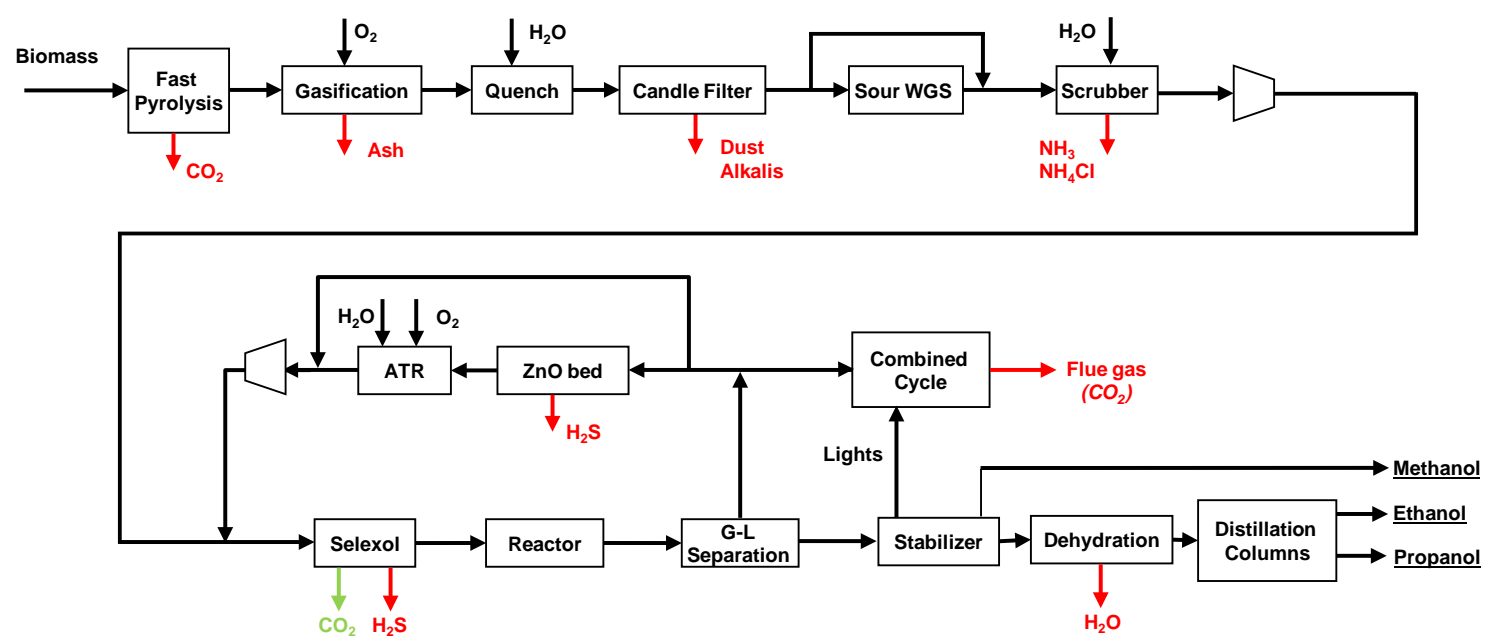

Figure 3. Process flowchart of the thermochemical production of ethanol and higher alcohols via direct synthesis (adapted from [6]).

Table 2. Process conditions for the direct synthesis of ethanol from syngas ( $\mathrm{MoS}_{2}$ Abengoa Bioenergy catalyst) [6]

\begin{tabular}{lcc}
\hline Temperature $(\mathrm{K})$ & 573 \\
Pressure (MPa) & & 9.0 \\
CO conversion (\%) & 35.3 \\
$\mathrm{H}_{2} / \mathrm{CO}$ molar ratio & & 1.0 \\
\hline Selectivity to product (\% molar) & & \\
& & 35.4 \\
& Ethanol & 7.5 \\
& Methanol & 4.2 \\
& Propanol & 17.7 \\
& Light gas & 35.2 \\
\hline
\end{tabular}

2.1.4. Case study 4: $2^{\text {nd }}$ generation ethanol via thermochemical processing (indirect route)

The direct synthesis of ethanol from syngas suffers from important limitations e.g. low selectivity, which reduces the efficiency of the ethanol production [27, 36]. Hence, the indirect synthesis via DME hydrocarbonylation has been proposed to produce ethanol from syngas with better efficiency as well as economics [7, 27, 37]. However, the indirect synthesis of ethanol 
from syngas is in a preliminary stage of development, therefore the DME hydrocarbonylation route is included in this study only as a potential long-term alternative.

The bases for the conversion of syngas into ethanol via DME hydrocarbonylation are summarized in Table 3 and the corresponding process flowchart is illustrated in Figure 4. In this study, only the best case of the previous assessment (i.e. CO/DME molar ratio 10:1) is included, which uses a combination of $\mathrm{Cu}-\mathrm{ZnO}$ and $\mathrm{H}$-Mordenite catalyst in a dual catalytic fixed-bed reactor [7].

\subsubsection{Ethanol dehydration to ethylene}

The dehydration of ethanol (Eq. (1)) is an established technology commercially available for the production of ethylene [2, 38-42]. In this study, the design of the dehydration process is based on commercial technology [43]. Table 4 shows the reaction conditions used for the modeling of the dehydration reactor applicable to case studies 1-4.

$\mathrm{C}_{2} \mathrm{H}_{5} \mathrm{OH} \rightarrow \mathrm{C}_{2} \mathrm{H}_{4}+\mathrm{H}_{2} \mathrm{O}$

Figure 5 presents the process flowchart for the ethanol dehydration plant. The ethanol feedstock is mixed with water in a 1:1 molar ratio, pumped and preheated before entering the dehydration reactor. The outlet stream from the dehydration reactor is cooled and compressed for dewatering and conditioned for the recovery of ethylene. The gas stream requires only two fractionation columns, i.e. a first column for $\mathrm{C}_{3-}$ and $\mathrm{C}_{4+}$ hydrocarbon splitting, and a second one for the removal of ethane and propylene. The final product stream contains 99.99\% (on a weight basis) ethylene with methane as the main impurity. Recovered hydrocarbons are fed to a gas combustor for thermal integration of the plant, although additional natural gas is required to satisfy the power integration of the plant.

\subsection{DME-to-olefins (case study 5)}

In this case study, DME instead of ethanol is used as the platform chemical for ethylene synthesis. The process has been modeled according to the bioliq ${ }^{\circledR}$ concept, which is currently being developed at the Karlsruhe Institute of Technology (KIT) and focuses on the conversion of low-grade lignocellulosic biomass, such as residual wood or straw, to synthetic fuels and other organic chemicals [44-46], as presented in Figure 6. The production of olefins (ethylene and propylene) from syngas via DME was previously modeled and assessed based on a large scale realization of the bioliq $^{\circledR}$ concept in Germany [8]. Modeling of previous processing stages (i.e. pyrolysis step, production of syngas by entrained flow gasification and syngas cleaning and conditioning) are described in [47, 48].

The process conditions bases for the conversion of syngas via DME into ethylene, propylene and LPG (light gas and butenes) are summarized in Table 5 and the process flowchart is shown 
in Figure 7. In this study, only the best case of the previous assessment is considered [8].Compared to case studies 1-4, in this case, propylene and LPG are co-produced. The biomass input is larger than in case studies 3 and 4 (see Figure 6).
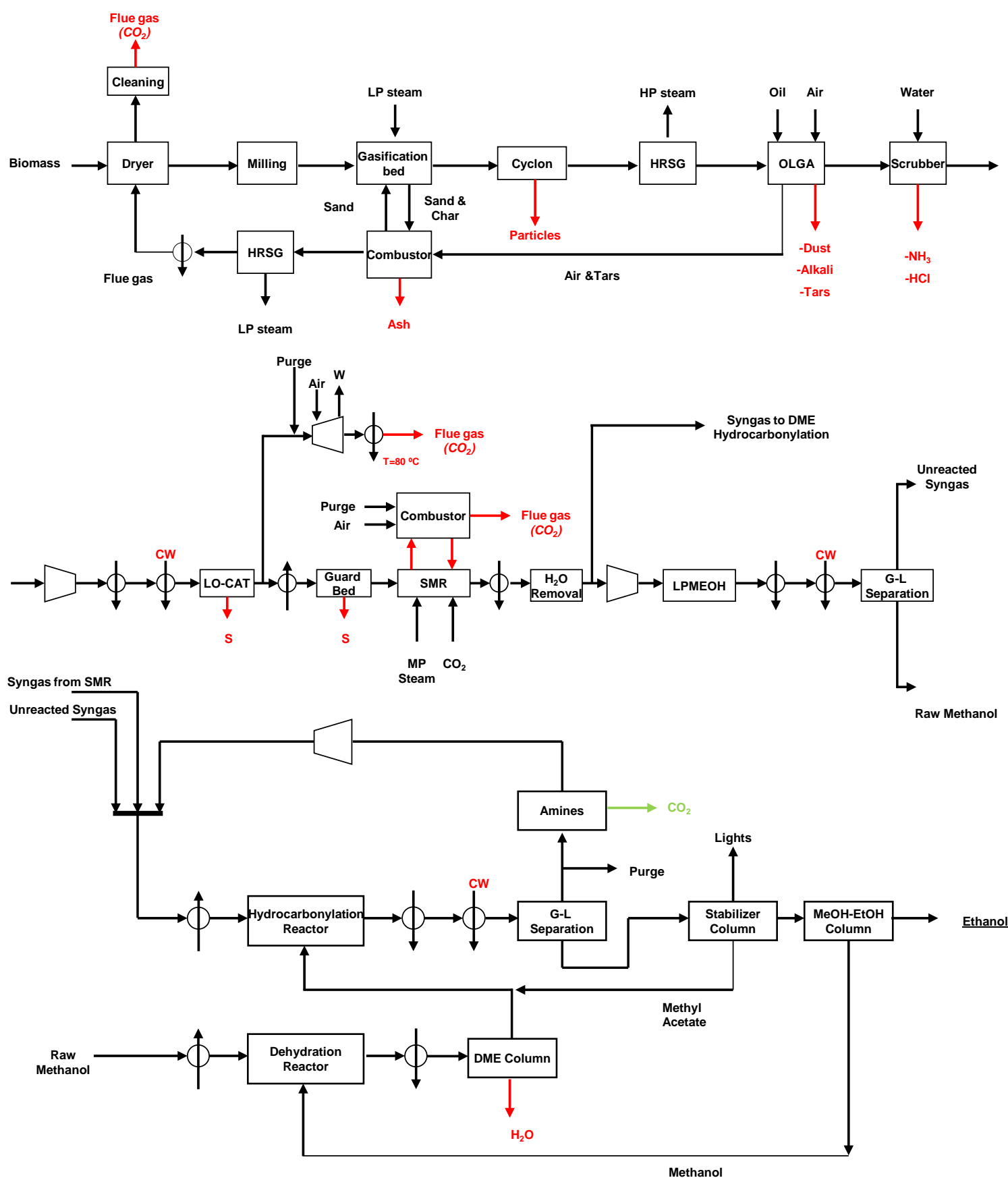

Figure 4. Process flowchart of the thermochemical production of ethanol via indirect synthesis (adapted from [7]). 
Table 3. Process conditions for the indirect synthesis of ethanol from syngas via DME hydrocarbonylation [7].

\begin{tabular}{|c|c|c|c|}
\hline \multirow{9}{*}{ Methanol synthesis } & \multicolumn{2}{|l|}{ Temperature (K) } & 523 \\
\hline & \multicolumn{2}{|l|}{ Pressure (MPa) } & 4.9 \\
\hline & \multicolumn{2}{|l|}{ CO conversion (\%) } & 31 \\
\hline & \multicolumn{2}{|l|}{$\mathrm{CO}_{2}$ conversion $(\%)$} & 9 \\
\hline & \multicolumn{2}{|l|}{$\mathrm{H}_{2} / \mathrm{CO}$ molar ratio } & 1.70 \\
\hline & \multirow{4}{*}{ Selectivity to product (\% molar) } & Methanol & 89.2 \\
\hline & & DME & 0.1 \\
\hline & & Methane & 0.1 \\
\hline & & $\mathrm{H}_{2} \mathrm{O}$ & 10.6 \\
\hline \multirow{4}{*}{ DME synthesis } & \multicolumn{2}{|l|}{ Temperature (K) } & 593 \\
\hline & \multicolumn{2}{|l|}{ Pressure (MPa) } & 2.0 \\
\hline & \multicolumn{2}{|l|}{ Methanol conversion (\%) } & 85 \\
\hline & \multicolumn{2}{|l|}{ Selectivity to DME } & 1 \\
\hline \multirow{8}{*}{ DME hydrocarbonylation } & \multicolumn{2}{|l|}{ Temperature (K) } & 493 \\
\hline & \multicolumn{2}{|l|}{ Pressure (MPa) } & 1.5 \\
\hline & \multicolumn{2}{|l|}{$\mathrm{H}_{2} / \mathrm{CO}$ molar ratio } & 1.57 \\
\hline & \multicolumn{2}{|l|}{ DME conversion (\%) } & 48 \\
\hline & \multirow{4}{*}{ Selectivity to product (\% molar) } & Methanol & 45.0 \\
\hline & & Ethanol & 38.0 \\
\hline & & Methyl acetate & 6.5 \\
\hline & & $\mathrm{CO}_{2}$ & 10.5 \\
\hline
\end{tabular}

Table 4. Process conditions for the dehydration reactor (adapted from [43]).

\begin{tabular}{|c|c|c|}
\hline Temperature (K) & & 613 \\
\hline Pressure (MPa) & & 0.48 \\
\hline Ethanol conversion & & 1 \\
\hline \multirow{7}{*}{ Carbon selectivity (\%) } & $\mathrm{CH}_{4}$ & 0.10 \\
\hline & $\mathrm{C}_{2} \mathrm{H}_{4}$ & 96.50 \\
\hline & $\mathrm{C}_{2} \mathrm{H}_{6}$ & 0.50 \\
\hline & $\mathrm{C}_{3} \mathrm{H}_{6}$ & 0.05 \\
\hline & Butenes & 2.40 \\
\hline & Acetaldehyde & 0.20 \\
\hline & Coke & 0.25 \\
\hline
\end{tabular}



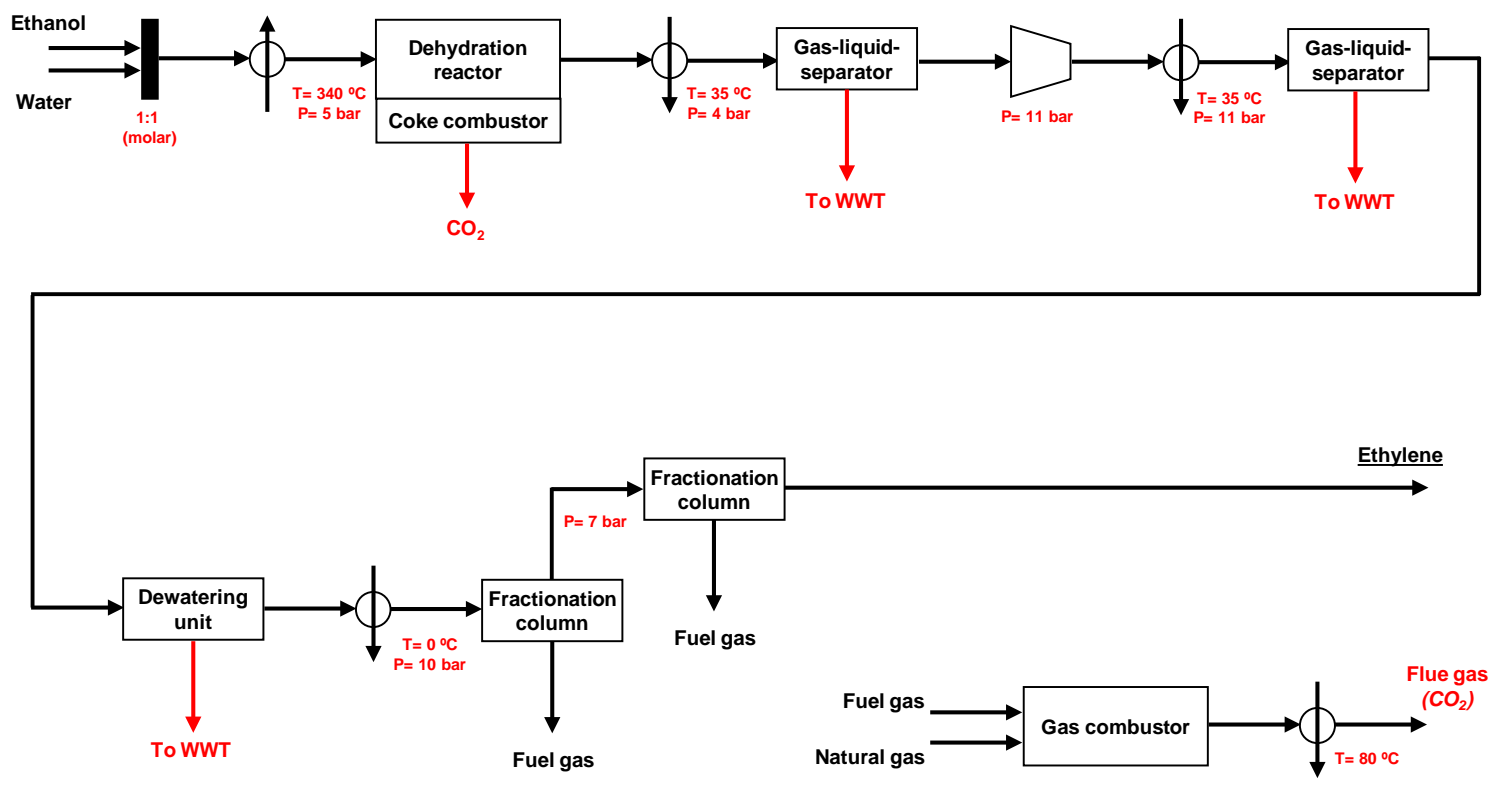

Figure 5. Process flowchart for the ethanol dehydration section.

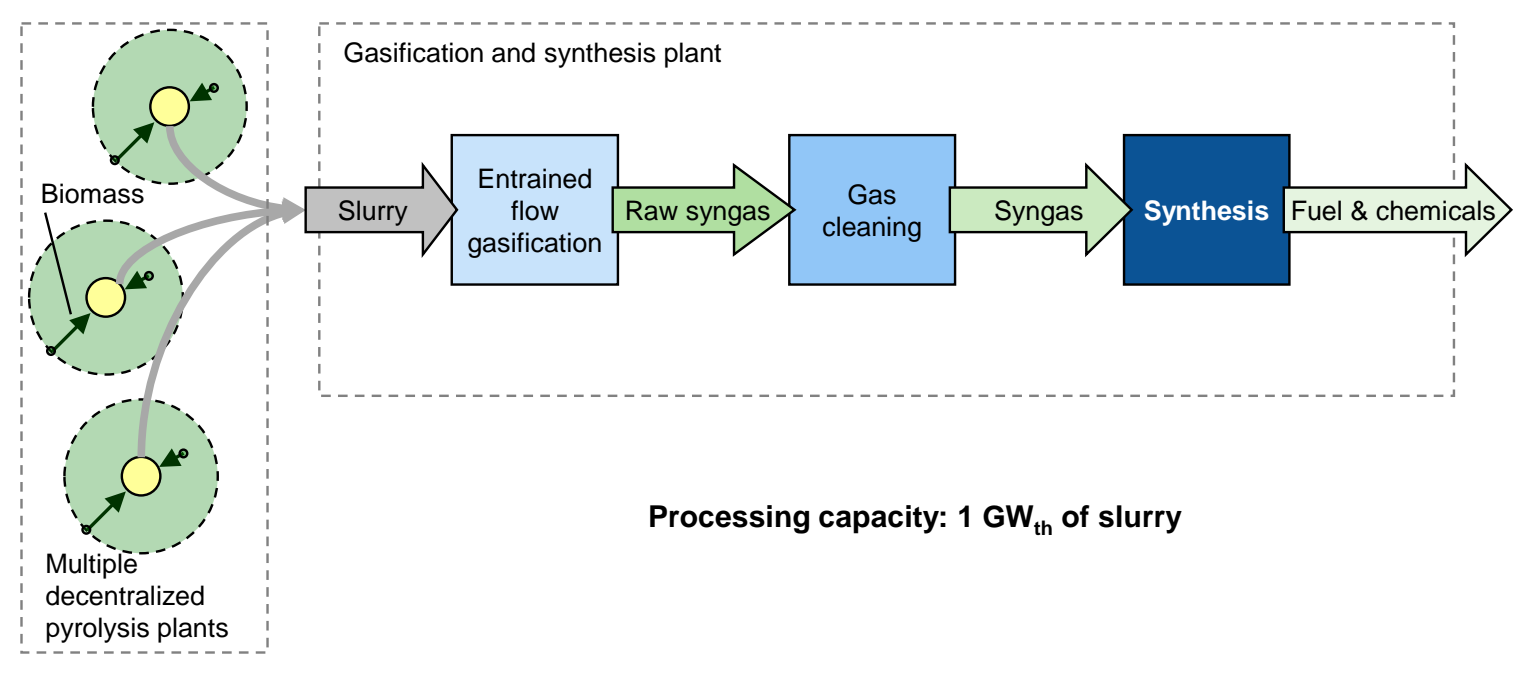

Figure 6. Overview of the bioliq ${ }^{\circledR}$ concept. 


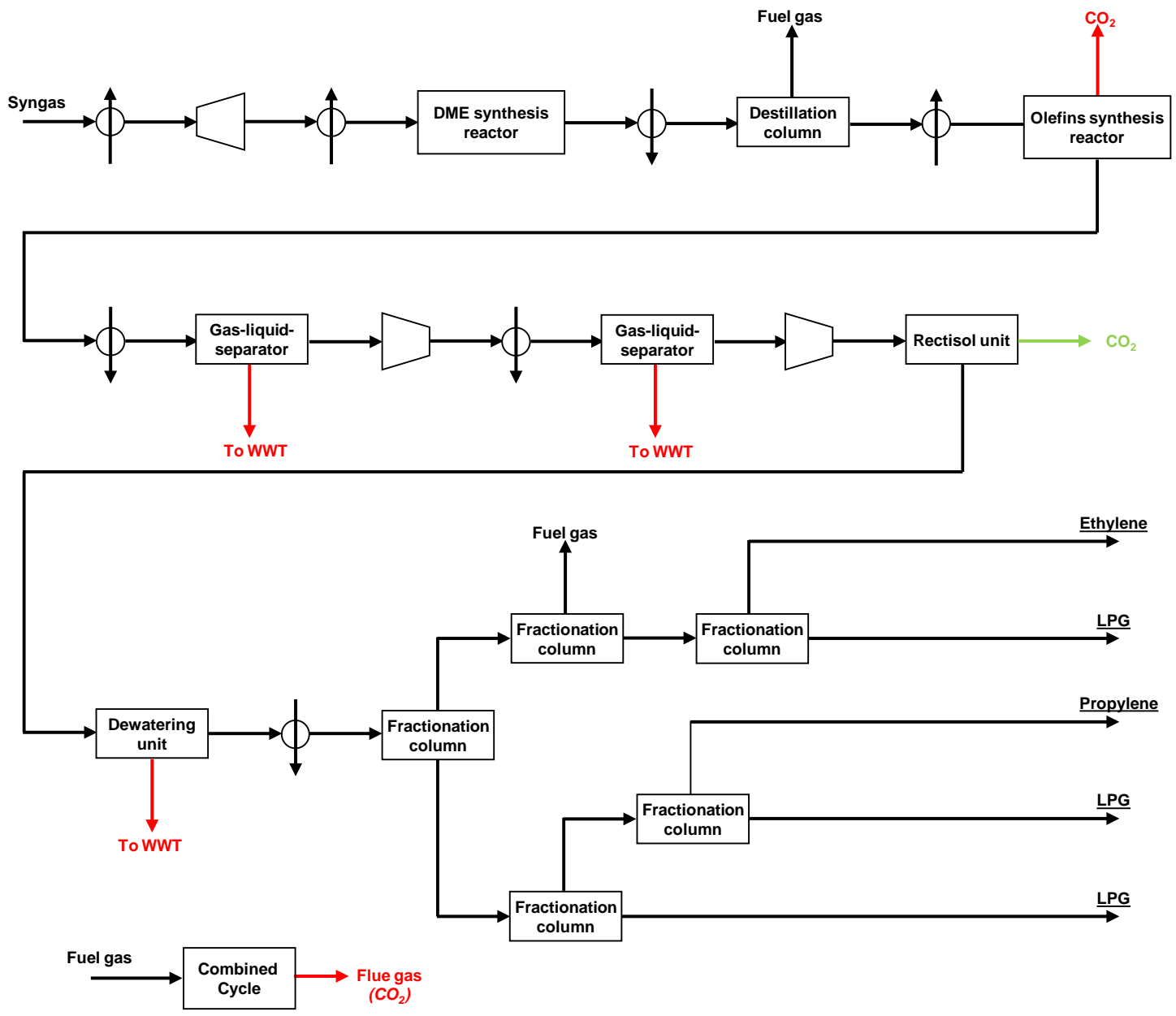

Figure 7. Process flowchart for the DME-to-olefins alternative (adapted from [8]).

Table 5. Process conditions for the ethylene production from syngas [8].

\begin{tabular}{|c|c|c|c|}
\hline \multirow{8}{*}{ DME synthesis } & Temperature (K) & & 523 \\
\hline & Pressure (MPa) & & 3.5 \\
\hline & CO conversion (\%) & & 85 \\
\hline & $\mathrm{H}_{2} / \mathrm{CO}$ molar ratio & & 1.0 \\
\hline & \multirow{4}{*}{ Product distribution (\% mass) } & DME & 49.3 \\
\hline & & Methanol & 1.4 \\
\hline & & $\mathrm{CO}_{2}$ & 48.8 \\
\hline & & $\mathrm{H}_{2} \mathrm{O}$ & 0.5 \\
\hline \multirow{8}{*}{ DME-to-olefins } & Temperature (K) & & 996 \\
\hline & Pressure (MPa) & & 0.4 \\
\hline & DME conversion & & 1 \\
\hline & Inert compounds (\% v/v) & & 39.1 \\
\hline & \multirow{4}{*}{ Hydrocarbon product distribution (\% mass) } & Ethylene & 45.1 \\
\hline & & Propylene & 38.7 \\
\hline & & Other light gases & 7.9 \\
\hline & & Butenes & 8.3 \\
\hline
\end{tabular}

\section{Methodology}


In order to conduct the technoeconomic assessment for the case studies, the mass and energy flows within the system boundaries are analyzed first. For this purpose, the process simulation software Aspen Plus is used. The mass and energy flow balancing builds up the foundation for the economic assessment. Fixed capital investment $(\mathrm{FCl})$ estimated for the considered case studies are derived using the determined capacities. Investment dependent costs together with personnel and other operating costs, as well as revenues from by-products, lead to specific production costs for the considered products in each case

\subsection{Process modeling}

Below, the most important criteria and assumptions used to simulate the considered case studies are outlined. The thermodynamic methods used to model the direct and indirect production of ethanol (case studies 3 and 4 ) are described in $[7,6]$. The dehydration of ethanol is modeled using the equation of state of Redlich-Kwong-Soave with Boston-Mathias modifications (RKS-BM) [49]. The thermodynamic methods used to model the DME-to-olefins conversion are described in [8]. The $\mathrm{CO}_{2}$ capture, when applicable, was previously modeled in their corresponding studies ([6] for case study $3,[7]$ for case study 4 and [8] for case study 5).

The specific product yields of the ethanol dehydration reactor (RYield) are calculated in a spreadsheet using technical data from [43] and result in the distribution of products presented in Table 1. An analogous procedure was used to specify product yields in the DME-to-olefins reactor [8]. In case study 3, product distribution was calculated using a proprietary $\mathrm{MoS}_{2}$ catalyst patented by Abengoa Bioenergy [6]. In case study 4, product distribution was calculated using experimental data [7].

For all case studies, rigorous fractionation columns (RadFrac) are used to give accurate results in the recovery of products and specifically for the ethylene recovery (modeled in this study). Column design and modeling in terms of molar split fractions, optimization of utility consumption and the thermal integration of columns were performed according to Smith [50] and thermal integration of the plant is described in $[6,7]$.

\subsection{Fixed capital investment estimate}

The economic assessment aims to determine ethylene production costs for the five case studies. To achieve this goal, the $\mathrm{FCl}$ for the ethanol dehydration, applicable in case studies 14 , is estimated in this study (case study 5 was previously analyzed [8]). All equipment components are designed according to the mass and energy flows. As previously mentioned, in case studies 1 and 2 the $\mathrm{FCl}$ is calculated for a range of plant capacities, whereas in case studies 3 and 4 the $\mathrm{FCl}$ is calculated for a determined plant capacity. The $\mathrm{FCl}$ for case study 5 (DME-to-olefins) was also estimated for a specific plant capacity [8]. 
The investment data for the main equipment components are summarized in Table 6. The investment data for equipment components not listed in Table 6, e.g. heat exchanger and distillation columns, are calculated according to $[51,53]$. The investment data are converted into $€$, using the yearly average exchange rate of the respective year [54], and updated to the year 2011. To account for price developments of equipment components, the price index from Kölbel/Schulze [55] is used. The presented results in section 4 for capital investment and production costs can be converted to US $\$$ by using the average 2011 exchange rate of 1.401 US\$/€.

Based on the investment data for the main equipment, the total capital investment of the ethanol dehydration plant can be estimated using ratio factors for direct and indirect capital investment according to [51], as explained in previous publications of the authors [48, 56]. Table 7 shows the assumed ratio factors for the control system, piping and further direct capital investments as well as the ratio factor for indirect capital investments, such as engineering or legal expenses. The ratio factors are selected according to process conditions, design complexity and required materials in this study. The applied ratio factor method implies uncertainties of $\pm 30 \%$ [51].

\subsection{Production cost estimate}

The annual production costs consist of investment dependent, personnel and operating costs, as well as revenues from by-products (only in the DME-to-olefins case). The investment dependent costs in turn are comprised of capital costs, maintenance and tax, as well as insurance and interests on working capital. Ethanol, biomass, catalysts, cooling water and electricity make up the consumption dependent costs of each case study. The composition of the annual production costs is calculated as in $[48,56]$, where further information can be found. In case studies 1 and 2, the annual production cost is also evaluated for their corresponding range of plant capacities.

The personnel requirement and costs estimation are based on previous studies $[44,56,57]$ based on the German workforce. Further economic assumptions used for the economic assessment of ethanol dehydration are presented in Table 8.

The production costs of ethanol in the case studies, including ethanol dehydration, have been selected subject to the origin of the ethanol. Table 9 shows the price of ethanol feedstock for each case. These production costs do not include transportation of ethanol to the dehydration plant gate.

The production cost of $2^{\text {nd }}$ generation ethanol via the direct route has been evaluated in [6] and the $2^{\text {nd }}$ generation ethanol via the indirect route in [7]. Both are based on biomass feedstock costs of 66 US\$ per dry ton. The production cost of ethylene in the DME-to-olefin case study 
has been evaluated in a previous publication [8] and is based on biomass feedstock costs of 71 $€$ per dry ton.

Table 6. Summary of investment data for main equipment components (ethanol dehydration plant).

\begin{tabular}{lccccc}
\hline \multicolumn{1}{c}{ Description } & $\begin{array}{c}\text { Base } \\
\text { scale }\end{array}$ & Unit & $\mathbf{M €}_{2011}$ & $\begin{array}{c}\text { Scaling } \\
\text { factor }\end{array}$ & Reference \\
\hline Dehydration reactor & 2386 & $\mathrm{kmol}$ of ethanol feed/h & 2.8 & 0.65 & {$[32]$} \\
Cryogenic system & 13.0 & $\mathrm{MW}_{\text {th }}$ & 10.3 & 0.70 & {$[51]$} \\
Compressor & 1.40 & $\mathrm{MW}_{\mathrm{e}}$ & 0.6 & 0.67 & {$[52]$} \\
Steam generator & 38 & $\mathrm{MW}_{\text {th }}$ & 6.5 & 0.60 & {$[51]$} \\
\hline
\end{tabular}

Table 7. Ratio factors for direct and indirect capital investments (adapted from [51]).

\begin{tabular}{lr}
\hline Direct investments & $\%$ \\
\hline Investment for installed equipment & 100 \\
Instrumentation and control & 24 \\
Piping & 46 \\
Electrical systems & 8 \\
Buildings & 12 \\
Yard improvements & 7 \\
Service facilities & 48 \\
Total direct investment & 245 \\
\hline Indirect investments & $\%$ \\
\hline Engineering and supervision & 22 \\
Construction expenses & 28 \\
Legal expenses & 3 \\
Contractor's fee & 15 \\
Contingency & 30 \\
Total indirect investment & 98
\end{tabular}


Table 8. Summary of economic assumptions.

\begin{tabular}{lcc}
\hline & Parameters for investment dependent costs & \\
\hline Capacity factor & $\%$ & 80 \\
Expected lifetime & Years & 20 \\
Depreciation (no scrap value) & Linear & - \\
Interest rate & $\%$ & 7.0 \\
Working capital & $\%$ of FCl & 5.0 \\
Maintenance costs (average) & $\%$ of FCl & $3.0-3.6$ \\
Insurance \& taxes & $\%$ of FCl & 2.0 \\
\hline & Prices for consumables & 85.95 \\
\hline Electricity [58] & $€ / \mathrm{MWh}$ & 44.50 \\
Natural gas [58] & $€ / \mathrm{MWh}$ & 0.26 \\
Cooling water [32] & $€ / \mathrm{m}^{3}$ & 0.32 \\
Waste water treatment [48] & $€ / \mathrm{m}^{3}$ & 113 \\
Dehydration catalyst [32, 59] & $€ / \mathrm{kg}$ & \\
\hline
\end{tabular}

Table 9. Summary of feedstock ethanol price for case studies 1-4.

\begin{tabular}{|c|c|c|c|}
\hline & & Price & Source \\
\hline \multirow{4}{*}{ Case study 1} & \multirow{4}{*}{$\begin{array}{c}\text { Commercial price of } \\
\text { bioethanol }{ }^{\mathrm{a}}\left(1^{\text {st }} \text { generation }\right. \\
\text { ethanol })\end{array}$} & $0.72-0.74 € / L$ & Europe [9] \\
\hline & & $2.41-2.68$ & \\
\hline & & US\$/gallon & 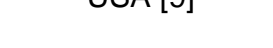 \\
\hline & & $0.51-0.62$ US\$/L & Brazil [9] \\
\hline \multirow{6}{*}{ Case study 2} & $2^{\text {nd }}$ generation biochemical & 0.95 US\$/L & Kazi et al. [10] \\
\hline & ethanol (via enzymatic & & \\
\hline & hydrolysis) & $0.0 \mathrm{E} / \mathrm{L}$ & 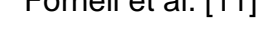 \\
\hline & $2^{\text {nd }}$ generation ethanol & & \\
\hline & biochemical ethanol (via & 1 US\$/gal & Coskata [25] \\
\hline & syngas fermentation) & & \\
\hline \multirow{3}{*}{ Case study 3} & $2^{\text {nd }}$ generation ethanol via & & \\
\hline & thermochemical processing & 0.710 US\$/L & Villanueva et al. [6] \\
\hline & (direct route) & & \\
\hline \multirow{3}{*}{ Case study 4} & $2^{\text {nd }}$ generation ethanol via & & \\
\hline & thermochemical processing & 0.555 US\$/L & Haro et al. [7] \\
\hline & (indirect route) & & \\
\hline
\end{tabular}

${ }^{a}$ Data referred to September 2012. 


\section{Results}

The following section compares the resulting mass and energy balances as well as fixed capital investment and production costs estimates for the considered case studies.

\subsection{Mass and energy balances}

Table 10 shows the results for the mass and energy balances for all case studies. In case studies 1 and 2, the ethanol input to the dehydration plant ranges from 150 to $500 \mathrm{ML} / y e a r$ and from 300 to $1000 \mathrm{ML} / \mathrm{year}$ respectively (see 2.1.1. and 2.1.2.). For case studies 3 and 4 , the ethanol input is the value from the corresponding assessments $[7,6]$ and the original biomass input is also included in the system boundaries. In case study 5 , all data refer to the previous publication by the authors [8], which has a fixed biomass input.

The energy efficiency to ethylene (and total products) in Table 10 is calculated according to Eq. (2), where the net input of electricity and natural gas are added when necessary. The electricity input is converted to an HHV equivalent assuming a conversion efficiency of $39 \%$.

For case studies 1-4, in those with a dehydration plant, an additional input of both natural gas and electricity is needed. In case study 5 , only electricity is imported to the plant. The energy efficiency of ethanol dehydration is quite high, so the low values of case studies 3 and 5 are due to the previous processing. Case study 4 achieves the best energy efficiency. However, the corresponding ethylene production is close to that in case study 5 , in which the efficiency to ethylene halves, as a result of the different biomass input in each case study. In case study 5, the co-production of propylene and LPG enhanced the global efficiency of process as in case study 4. Case study 3 achieves the lowest efficiency despite the co-production of higher alcohols.

Energy efficiency $(H H V)=\frac{\operatorname{product}(s)\left(M W_{t h}\right)}{\text { biomass }\left(M W_{t h}\right)+\frac{\text { electricityconsumed }\left(M W_{e}\right)}{0.39}+\text { natural gas }\left(M W_{t h}\right)}$ 
Table 10. Mass and energy balances for the considered case studies.

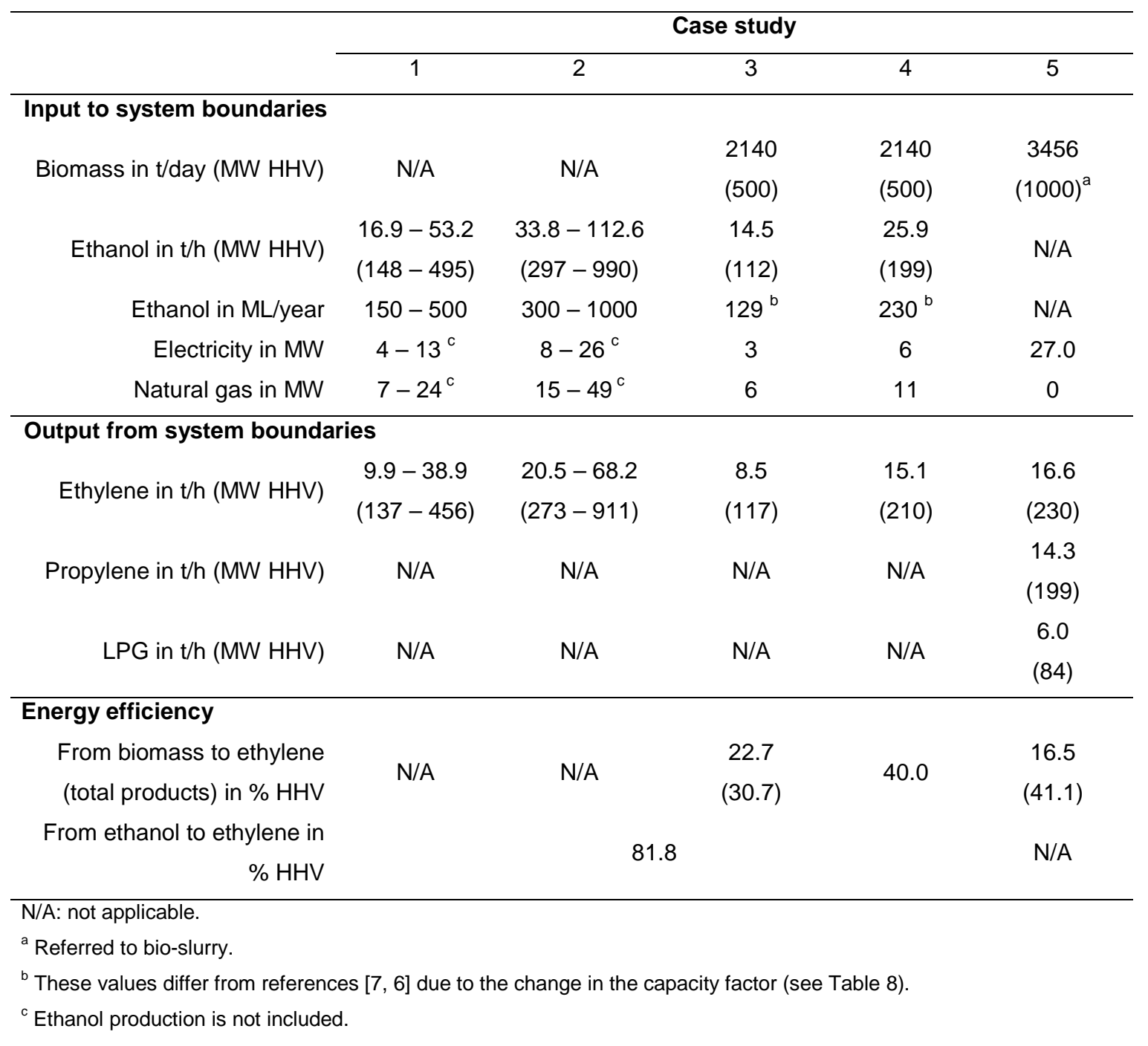

\subsection{Fixed capital investment}

The results of the fixed capital investment $(\mathrm{FCl})$ estimation corresponding to the system boundaries of this study are illustrated in Figure 8 and Figure 9 . The $\mathrm{FCl}$ of case studies 1 and 2 is presented for both extremes of considered plant capacity (see Table 10). The $\mathrm{FCl}$ for case studies 3-5 is notably larger than the $\mathrm{FCl}$ for case studies 1 and 2, which is a consequence of the different system boundaries used in the assessment (see Figure). In order to compare the $\mathrm{FCl}$, the dehydration plant of case studies 3 and 4 is also shown separately in Figure. The $\mathrm{FCl}$ of case study 5 is $31 \%$ and $72 \%$ larger compared to case studies 4 and 3, respectively. This difference is mainly due to the different capacities of biomass processing in these cases. 


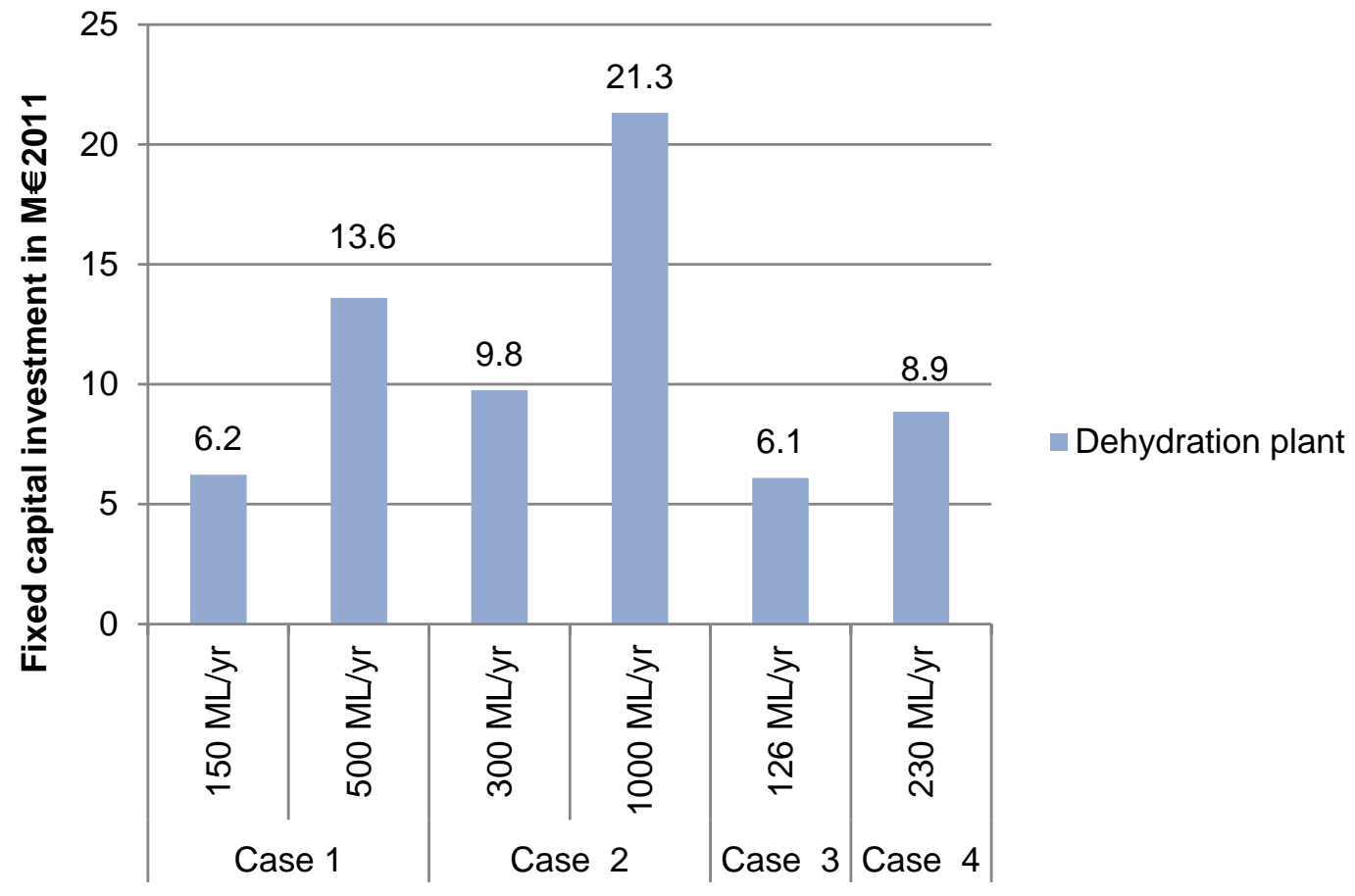

Figure 8. Fixed capital investment for the dehydration plant in case studies 1-4.

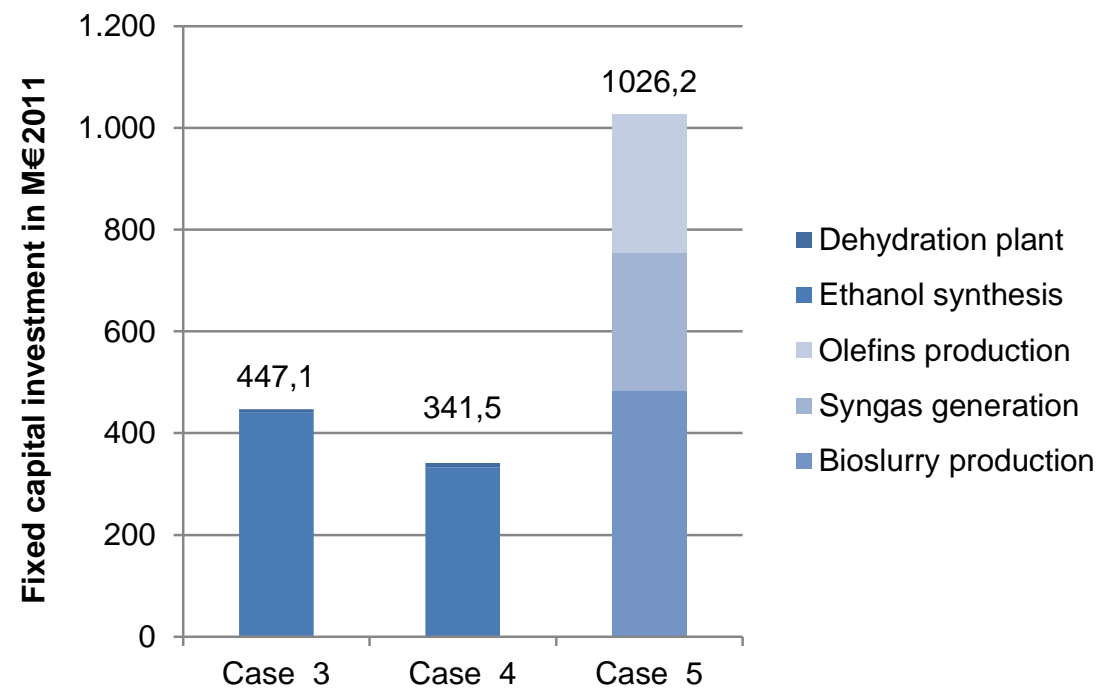

Figure 9. Fixed capital investment for case studies 3-5.

\subsection{Production cost estimate}

Figure 10 shows the specific production cost of ethylene for all alternatives in case study 1, i.e. using commercial prices from the EU, USA and Brazil, and for both extremes of plant capacities. Obviously, the lower the considered price of ethanol, the lower the production cost of ethylene. The contribution of ethanol cost to the total production cost of ethylene is about $91 \%$ for the lowest capacity using European ethanol and about $85 \%$ for the highest capacity using Brazilian ethanol. 
Figure 11 shows the specific production cost of ethylene for all alternatives in case study 2, i.e. using estimated ethanol prices based on $2^{\text {nd }}$ generation processes and for both extremes of plant capacities. As in case study 1 , the price of ethanol feedstock is critical for the production costs of ethylene. For $2^{\text {nd }}$ generation processes based on enzymatic hydrolysis, the production costs of ethylene ranges are about the same or slightly larger than in case study 1 . However, if the considered price for ethanol via syngas fermentation were accurate, then this process could produce ethylene at a half cost compared to using commercial Brazilian ethanol.

Figure 12 shows the specific production cost of ethylene for all alternatives in case studies 3-5. The lowest value corresponds to case study 4 and the highest to case study 3 . The differences between both cases are a result of the lower price of ethanol in case study 4 and the higher capacity of the dehydration plant. In case study 5, syngas, instead of ethanol, is the main contribution to the production costs of ethylene and represents $85 \%$ of the total production cost (revenues excluded).

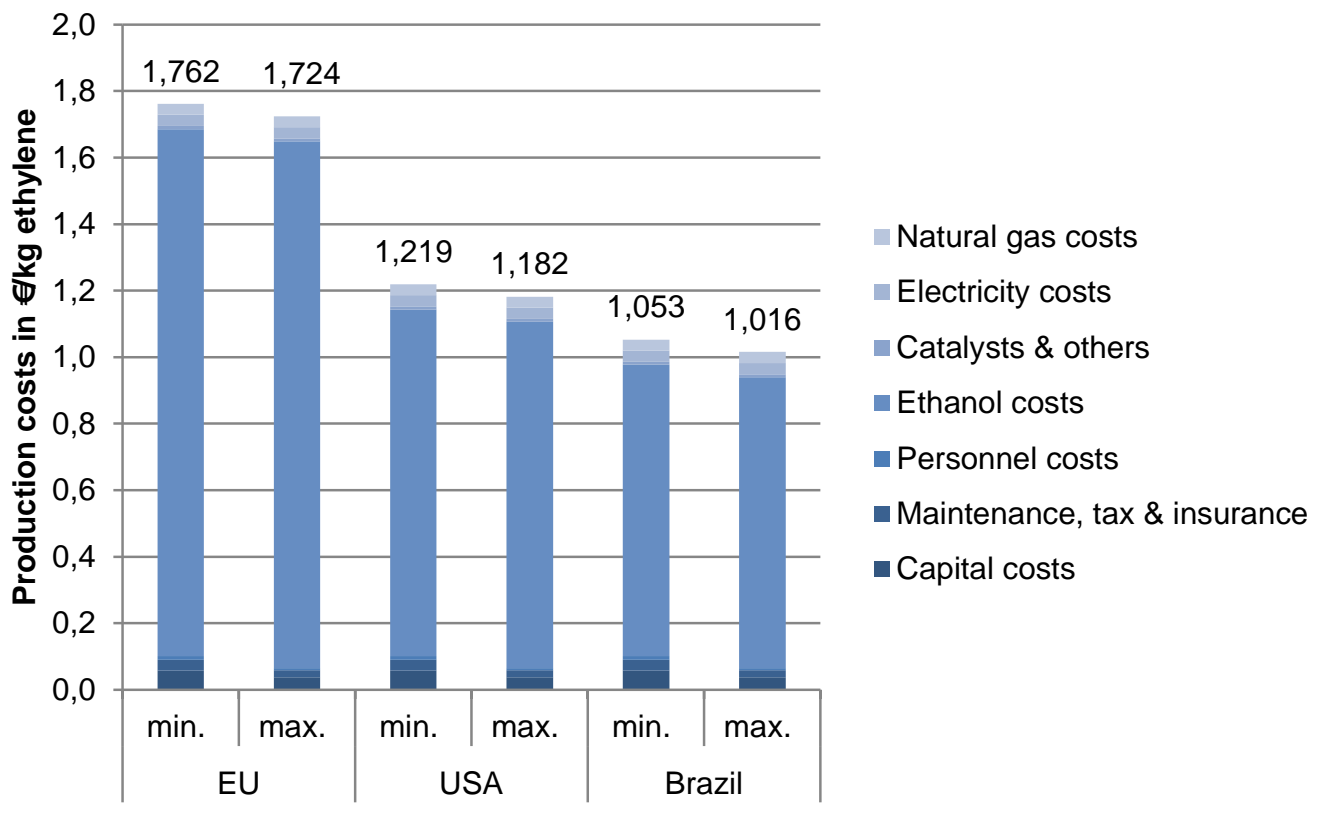

Figure 10. Specific production costs for case study 1. 


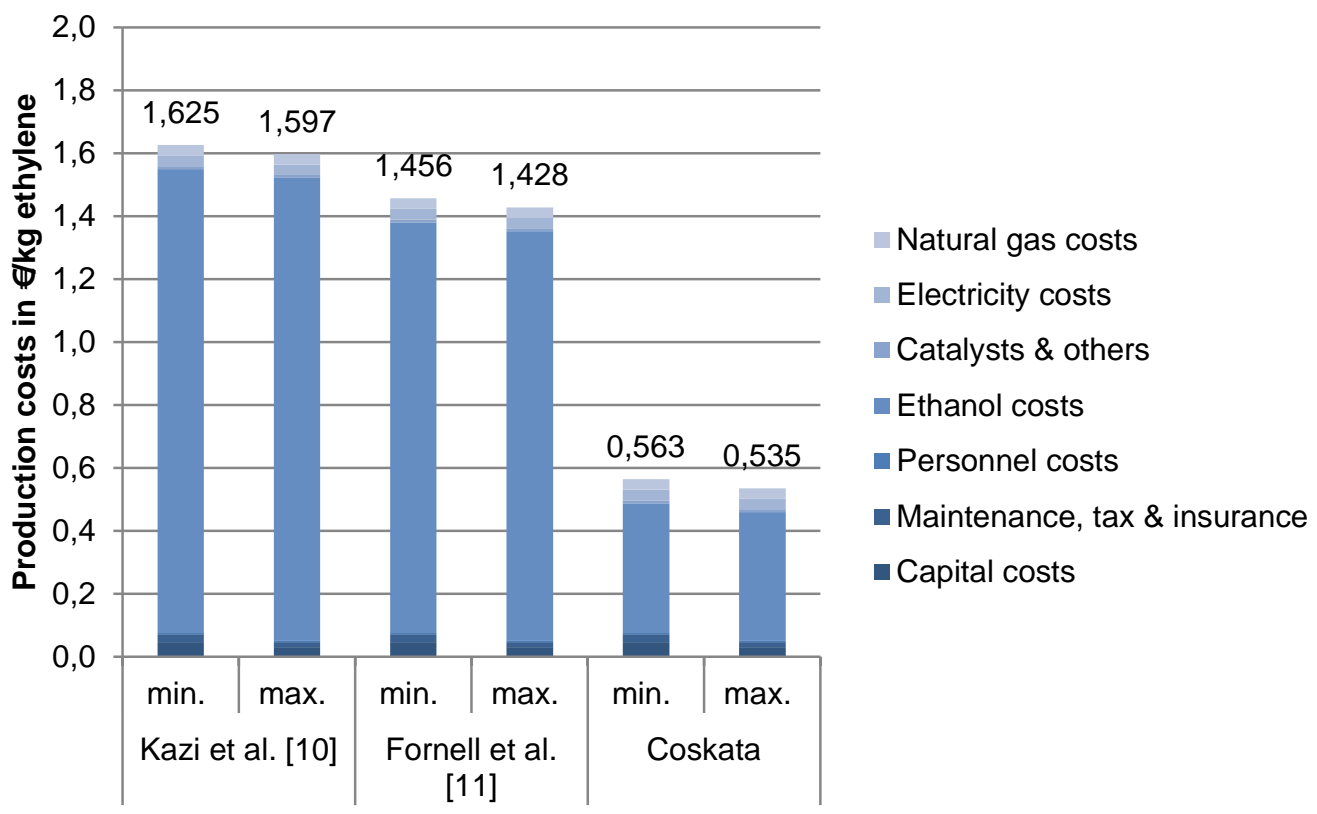

Figure 11. Specific production costs for case study 2.

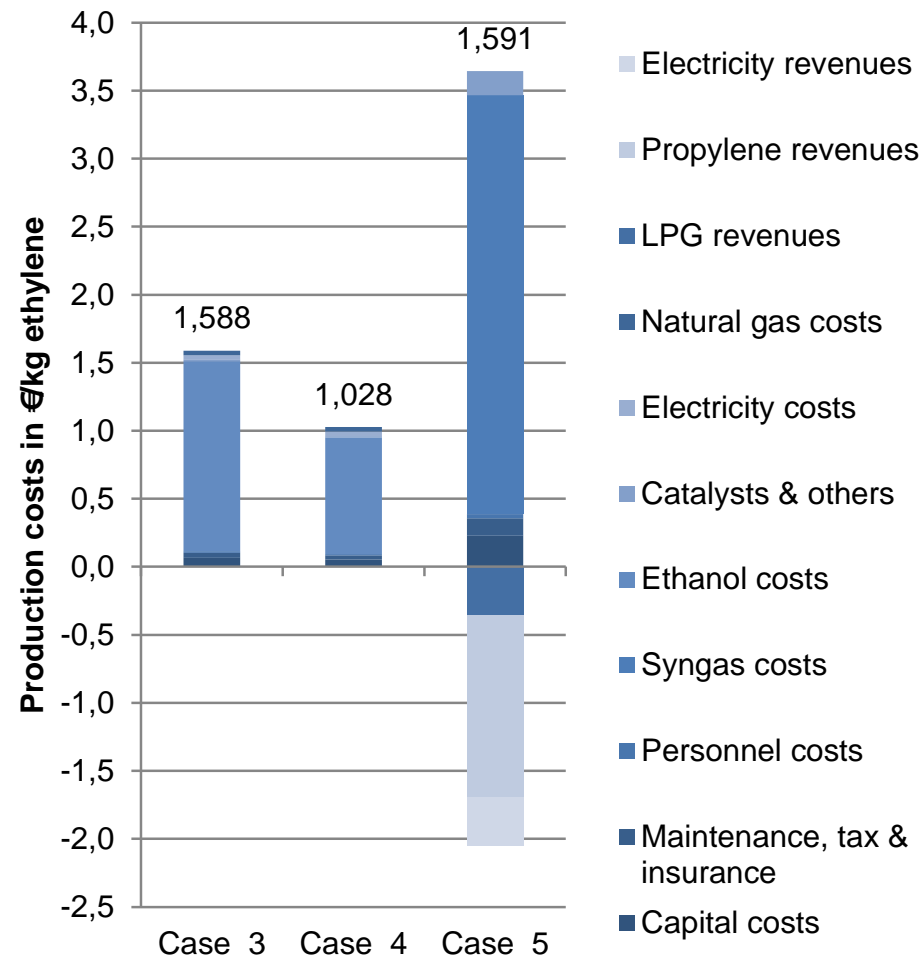

Figure 12. Specific production costs for case studies 3-5. 


\section{Discussion}

The production of ethylene from ethanol is highly dependent on the price of ethanol feedstock (minimum $85 \%$ of production cost), which should be below $0.45 € / L$ in order to achieve profitability regardless of the origin of the ethanol (case studies 1-4). This ethanol price is significantly below the current price of European ethanol, similar to USA ethanol and higher than Brazilian ethanol. Nevertheless, the origin of the ethanol plays a crucial role in the future development of processes using ethanol as a platform chemical. The availability of biomass, which is actually the bottleneck for all biomass-derived products, along with the future regulation of biofuels, are the keys to the development of future bio-ethylene production. Despite the higher production cost of ethylene in case study $2\left(2^{\text {nd }}\right.$ generation ethanol via enzymatic hydrolysis), the future regulations on biofuels could plunge the profit of current $1^{\text {st }}$ generation ethanol by withdrawing current subsidies or limiting biomass availability. Moreover, the volatility of the ethylene price brings more uncertainty regarding the profitability of an ethanol-to-ethylene plant. For the DME-to-olefins case, the production of ethylene is not related to that of ethanol, the process is well integrated and includes the co-production of propylene and LPG. However, the uncertain availability of cheap lignocellulosic biomass and the volatility of the ethylene market price are still applicable in this case.

The production of ethylene from biomass is profitable if Brazilian ethanol is used. In the case of using ethanol via thermochemical processing (only for indirect synthesis, case study 4), the resulting ethylene production costs are also below the minimum ethylene market price in 2011 and 2012 (about $1100 € / \mathrm{t}$ ). However, if only the currently feasible processes for the production of ethylene from biomass are considered, the use of Brazilian ethanol would be most likely, as demonstrated by Braskem in their green-polyethylene plant [14]. The use of bio-ethanol for the production of chemicals reveals a controversy about the possible uses of bioethanol. Should the current use of bioethanol as a renewable fuel be diverted into the production of chemicals or should other new uses of bioethanol (as a platform chemical) be satisfied exclusively with the increase in bioethanol production? Implications of this controversy are quite serious, since the alternative uses of ethanol as a platform chemical might take over the up-to-date paradigm of bioethanol as one of the most important biofuels for the future.

\subsection{Integration of ethylene production with ethanol production plants}

As mentioned in section 2.1.1., the integration of ethylene production with an existent ethanol production plant has been disregarded in this study. The main reason is the economies of scale (current ethanol plants have a plant capacity of around $50 \mathrm{ML} / \mathrm{year}$ [9]). However, the integration of a dehydration plant in an ethanol production facility could benefit from important advantages if both plants are simultaneously designed and operated as a whole. Like in a dehydration plant, the ethanol stream must be diluted with water (see section 2.1.5.). If the whole production of ethanol was fed to the dehydration plant, no azeotropic distillation would be needed; which would lead to an important reduction in both investment and operating costs. The product 
stream from biomass fermentation would only require a soft distillation in order to enhance the concentration of ethanol up to the dehydrator requirements (see Table 4). The benefits of this integration were first commented on in the BETE (BioEthanol-To-Ethylene) process in the 1980s [12].

\subsection{Integration of BECCS and comparison of the case studies}

For the inventory of $\mathrm{CO}_{2}$ emissions, only those within the system boundaries of this study are taken into account; except for case studies 1 and 2, where estimations for the synthesis of ethanol are also given. It is considered that only the $\mathrm{CO}_{2}$ that is already captured in these cases or available at high purity will be suitable for transport and storage (marked green in Figure 3 , Figure 4 and Figure 7). Hence, other sources of $\mathrm{CO}_{2}$, like combustion gases are disregarded since they represent neither an advantage from CCS in power plants nor a benefit to the process economics. The extra energy input for $\mathrm{CO}_{2}$ compression is assumed to come from the grid. The calculations of the $\mathrm{CO}_{2}$ sequestration costs (comprising compression, transportation and storage) are according to the methodology described in section 3.

Table 11 shows the summary of total $\mathrm{CO}_{2}$ emissions and integration of BECCS in the case studies. The results of the integration of BECCS are in agreement with a recent study by Meerman et al. [60], which assesses the sequestration of $\mathrm{CO}_{2}$ in facilities using a steam methane reformer (as in case study 4), and in general with the data published by the IEA in 2011 [3], where the reduction of the capital cost for $\mathrm{CO}_{2}$ capture (pre-combustion) is balanced with the inclusion of transportation and storage costs. The available $\mathrm{CO}_{2}$ for storage fluctuates from about $70 \%$ of total $\mathrm{CO}_{2}$ emissions in case study 3 , where most $\mathrm{CO}_{2}$ is captured by the Selexol unit (see Figure 3); to about $24 \%$ in case study 4, where the Amines unit is used only to remove the excess $\mathrm{CO}_{2}$ in the ethanol synthesis loop (see Figure 4). In case study 5, there are two sources of $\mathrm{CO}_{2}$ available for storage, both using Rectisol technology (see Figure 5). Although each case study uses a different capture technology, the $\mathrm{CO}_{2}$ sequestration cost, i.e. the costs of capture (only compression), transportation and geological storage, are slightly different. In case study 2, considering the biochemical production of ethanol (where total emissions of $\mathrm{CO}_{2}$ are externally given), it is possible to calculate the available $\mathrm{CO}_{2}$ for storage (19\% of total $\mathrm{CO}_{2}$ emissions), which is much lower than in the case of thermochemical processing (case studies 3-5). 
Table 11. Summary of $\mathrm{CO}_{2}$ emissions and integration of BECCS in the case studies.

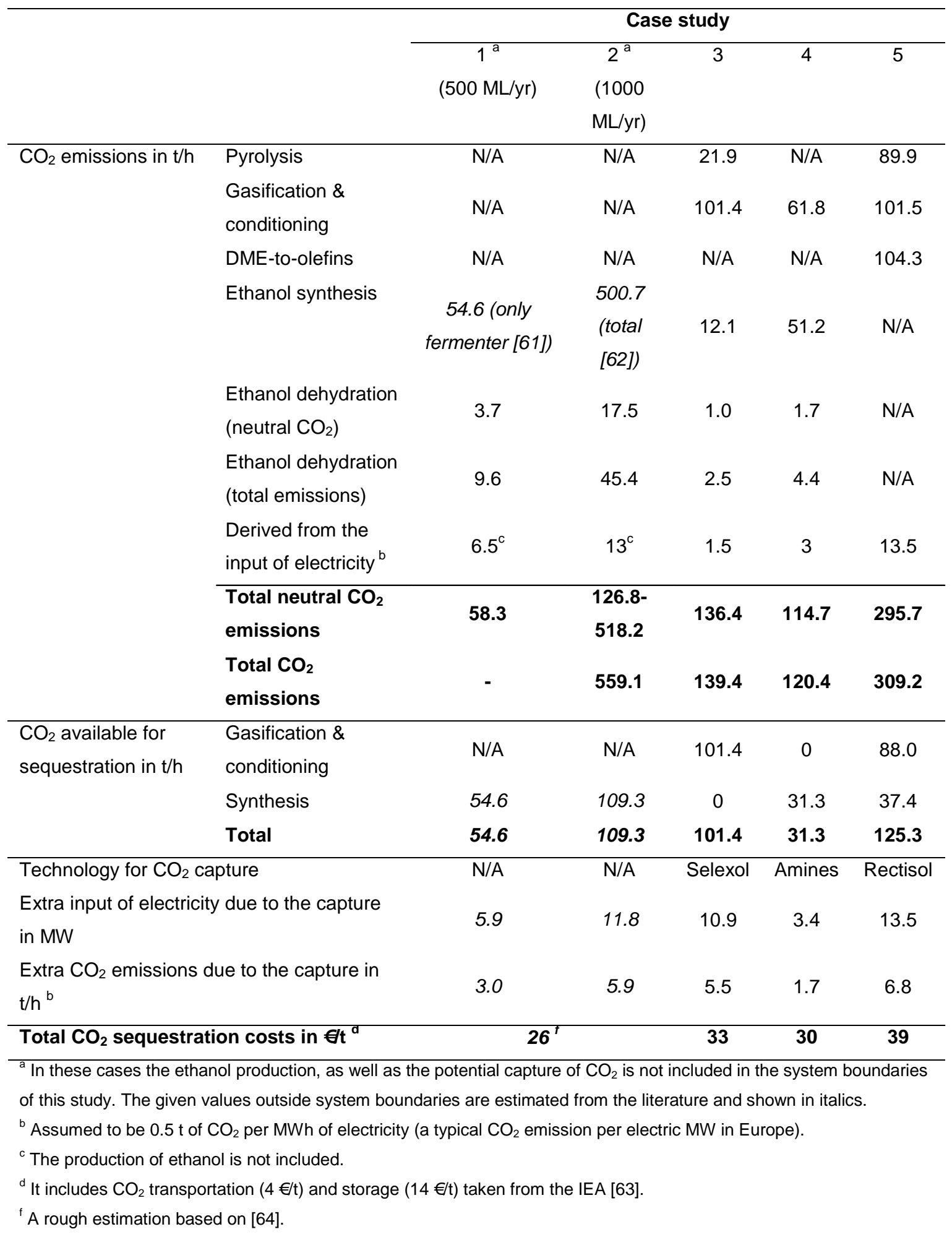




\subsection{Comparison of all case studies in terms of BECSS integration and plant capacity}

For case studies 1 and 2, the sensitivity is represented as a function of the plant capacity, whereas for case studies 3-5 it is represented as a function of the selling price of $\mathrm{CO}_{2}$ credits. It must be noted that the possibility of extra revenues due to $\mathrm{CO}_{2}$ sequestration is not taken into account for case studies 1 and 2. Although the capture and storage of $\mathrm{CO}_{2}$ in these processes seems favorable, the small capacity and the geographical dispersion of ethanol plants are the main obstacles for its implementation [61, 64]. In comparison to cases considering thermochemical processing, Lindfeldt and Westermark [65] concluded that $\mathrm{CO}_{2}$ capture is more realizable. Currently, the main uses of $\mathrm{CO}_{2}$ from ethanol plants are not sequestration but food processing and preservation (e.g. carbonated beverages and refrigeration), representing more than $30 \%$ of the merchant $\mathrm{CO}_{2}$ market in USA [64].

Figure 13 shows a global outlook on the sensitivity analysis for all case studies considering BECCS. In order to compare all the case studies with each other and with the commercial price of ethylene, a transition zone (gray) has been added representing the variation of the ethylene market price from 2011 to the present along with the price of ethanol feedstock for all alternatives in case studies 1-4. For $1^{\text {st }}$ generation ethanol (case study 1 ) the production of ethylene is profitable at current market prices, if Brazilian ethanol is used as feedstock. European ethanol should be disregarded, as it would produce ethylene at costs higher than the current commercial price. In the case of ethanol from USA, the resulting ethylene production cost would lie in the range of the ethylene market price between 2011 and 2012. The future price of $2^{\text {nd }}$ generation ethanol (case study 2 ) is still uncertain so the curves are illustrated using dashed lines for the alternatives via enzymatic hydrolysis and a dotted line for the more uncertain case of syngas fermentation (Coskata). In comparison to case study 1 , the curves decrease downwards more steadily, as a result of the higher considered capacities. Only in the case of ethanol from syngas fermentation, might the resulting ethylene be cost-competitive and it would halve the current ethylene market price. For ethanol using the thermochemical processing of biomass and direct synthesis from syngas (case study 3), the resulting ethylene price is significantly above the market price. However, assuming the possibility of selling $\mathrm{CO}_{2}$ credits, the process would produce cost-competitive ethylene with $\mathrm{CO}_{2}$ credits above $75 €$ per tonne of sequestered $\mathrm{CO}_{2}$. In the similar case of ethanol from thermochemical processing but using indirect synthesis (case study 4), the process is profitable even without the sale of $\mathrm{CO}_{2}$ credits. For case study 5 , using thermochemical processing of biomass and syngas conversion via DME-to-olefins, the results are close to those of case study 3, except for the required $\mathrm{CO}_{2}$ credits price. In this case, a $\mathrm{CO}_{2}$ credit price above $150 € / \mathrm{t}$ would be needed to achieve a costcompetitive production of ethylene. 


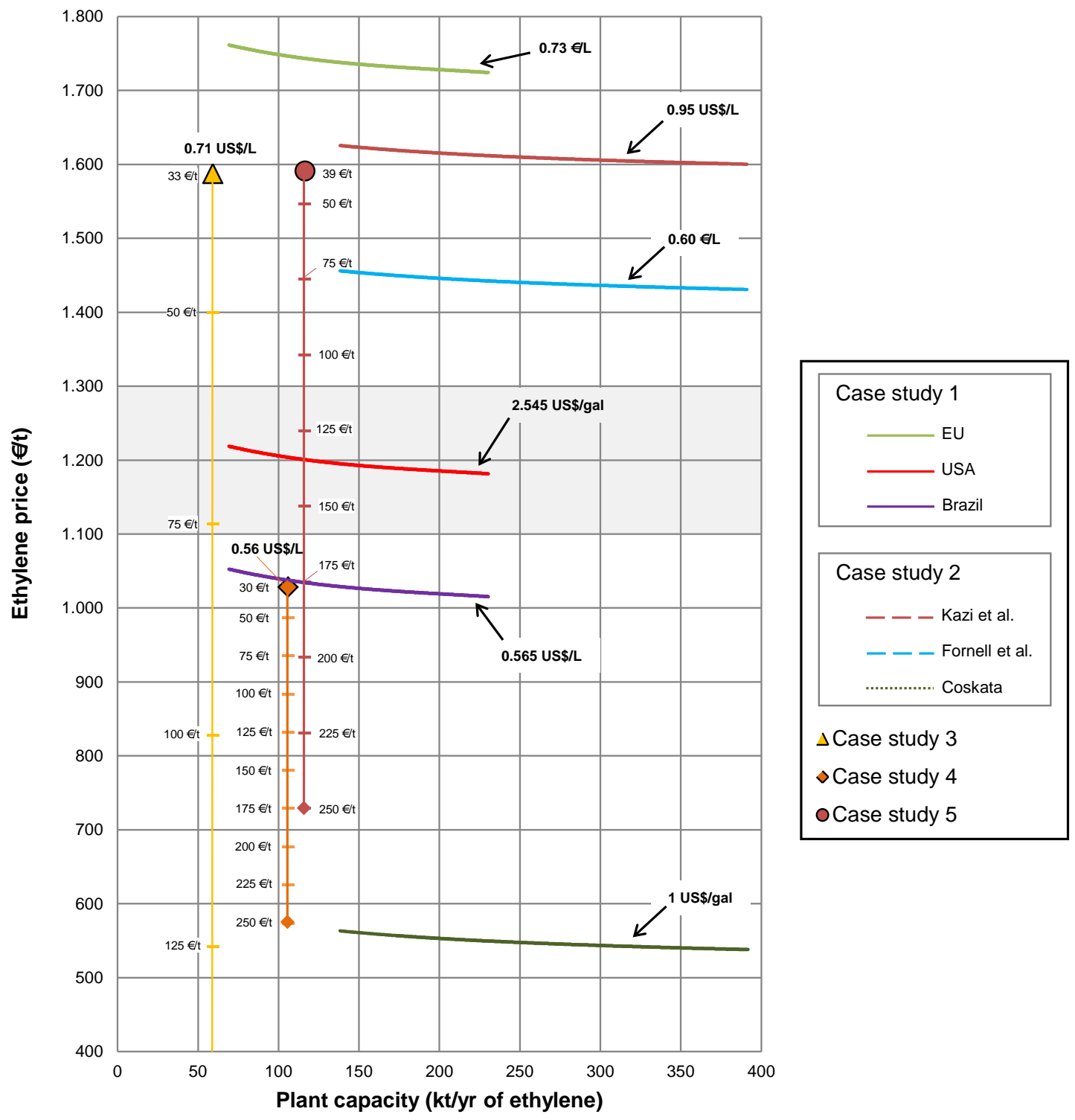

Figure 13. Sensitivity of ethylene price for the case studies as a function of plant capacity and market price of future $\mathrm{CO}_{2}$ credits (based on sequestrated $\mathrm{CO}_{2}$ ). 


\section{Conclusions}

The presented work assesses the technical and economic viability of potential processes to produce ethylene from biomass using currently or potentially applicable technologies using technical and economic data from the bioliq ${ }^{\circledR}$ project. Two main routes are identified to this end using ethanol or DME as platform chemicals. For all case studies using ethanol, it can be concluded that the price of ethanol feedstock is crucial. Only Brazilian ethanol and the estimated price of ethanol via the indirect synthesis of syngas would enable the cost-competitive production of ethylene. However, the development of new uses for ethanol different to the biofuel application, reveals a controversy if current bioethanol should be diverted into the production of chemicals or these new uses should be satisfied only with a future increase in bioethanol production. For the case study using DME, the resulting price of ethylene is above the commercial ethylene price, but it does not require ethanol. If BECCS (Bioenergy with Carbon Capture and Storage) is taken into account for the case studies, the results would be substantially enhanced.

\section{Acknowledgments}

This work has been funded by the Spanish Ministry of Economy and Innovation and carried out in the framework of the project "BIOTER" (Proyecto de Investigación Fundamental No-Orientada; ENE2012-31598). The grant given by the Spanish Ministry of Education (FPU Program; AP2010-0119) to P. Haro is acknowledged. 


\section{References}

[1]. B. Thinnes, Bio-based polymers could be next big thing, Hydrocarbon Processing. 2012;91(2):19-20.

[2]. Ethylene, Ullmann's Encyclopedia of Industrial Chemistry. doi: 10.1002/14356007.a10_045.pub3

[3]. Cost and performance of carbon dioxide capture for power generation. Working Paper. International Energy Agency. OECD/IEA, 2011.

[4]. ICIS. Chemical Prices, Key Indicators, Data Bank. ICIS Chemical Business; from 2006 to 2011.

[5]. Mineralölwirtschaftsverband e.V. (MWV). http://www.mwv.de/index.php/daten/statistikenpreise (accessed October 2012)

[6]. A.L. Villanueva Perales, C. Reyes Valle, P. Ollero, A. Gómez-Barea, Technoeconomic assessment of ethanol production via thermochemical conversion of biomass by entrained flow gasification, Energy. 2011;36(7):4097-108.

[7]. P. Haro, P. Ollero, A.L. Villanueva Perales, C. Reyes Valle, Technoeconomic assessment of lignocellulosic ethanol production via DME (dimethyl ether) hydrocarbonylation, Energy. 2012;44(1):891-901.

[8]. P. Haro, F. Trippe, R. Stahl, E. Henrich, Bio-syngas to gasoline and olefins via DME - A comprehensive techno-economic assessment. Applied Energy. 2013. doi: 10.1016/j.apenergy.2013.03.015

[9]. F.O. Licht's World Ethanol and Biofuels Report. Vol. 11 N 01; 6 Sep. 2012.

[10]. F.K. Kazi, J.A. Fortman, R.P. Anex, D.D. Hsu, A. Aden, A. Dutta, et al., Techno-economic comparison of process technologies for biochemical ethanol production from corn stover, Fuel. 2010;89(SUPPL. 1):S20-8.

[11]. R. Fornell, T. Berntsson, A. Åsblad, Process integration study of a kraft pulp mill converted to an ethanol production plant - part B: Techno-economic analysis, Appl Therm Eng. 2012;42:179-90.

[12]. R. Le Van Mao, T.M. Nguyen, G.P. McLaughlin, The bioethanol-to-ethylene (B.E.T.E.) process, Applied Catalysis. 1989;48(2):265-77.

[13]. http://www.ethanolproducer.com/articles/8617/feeding-the-chemical-market (accessed October 2012)

[14]. http://www.chemicals-technology.com/projects/braskem-ethanol/ (accessed October 2012)

[15]. S.I. Mussatto, G. Dragone, P.M.R. Guimarães, J.P.A. Silva, L.M. Carneiro, I.C. Roberto et al., Technological trends, global market, and challenges of bio-ethanol production, Biotechnol Adv. 2010;28(6):817-30.

[16]. New Commission proposal to minimise the climate impacts of biofuel production. European Commission Press Release (Reference: IP/12/1112 Event Date: 17/10/2012) http://europa.eu/rapid/press-release_IP-12-1112_en.htm (accessed October 2012)

[17].R.E.H. Sims, W. Mabee, J.N. Saddler, M. Taylor, An overview of second generation biofuel technologies, Bioresour Technol. 2010;101(6):1570-80.

[18]. J.Y. Zhu, X.S. Zhuang, Conceptual net energy output for biofuel production from lignocellulosic biomass through biorefining, Progress in Energy and Combustion Science. 2012;38(4):583-98.

[19]. J.J. Cheng, G.R. Timilsina, Status and barriers of advanced biofuel technologies: A review, Renewable Energy. 2011;36(12):3541-9.

[20]. V. Menon, M. Rao, Trends in bioconversion of lignocellulose: Biofuels, platform chemicals \& biorefinery concept, Progress in Energy and Combustion Science. 2012;38(4):522-50.

[21]. B. Amigun, D. Petrie, J. Gorgens, Economic risk assessment of advanced process technologies for bioethanol production in South Africa: Monte Carlo analysis, Renewable Energy. 2011;36(11):317886.

[22]. B. Amigun, D. Petrie, J. Görgens, Feedstock and technology options for bioethanol production in South Africa: Technoeconomic prefeasibility study, Energy and Fuels. 2012;26(9):5887-96. 
[23]. D. Humbird, R. Davis, L. Tao, C. Kinchin, D. Hsu, A. Aden et al., Process Design and Economics for Biochemical Conversion of Lignocellulosic Biomass to Ethanol Dilute-Acid Pretreatment and Enzymatic Hydrolysis of Corn Stover, Technical Report NREL/TP-5100-47764. May 2011. http://www.nrel.gov/biomass/pdfs/47764.pdf

[24]. E. Gnansounou, A. Dauriat, Techno-economic analysis of lignocellulosic ethanol: A review, Bioresour Technol. 2010;101(13):4980-91.

[25]. M. Bryner, Coskata makes ethanol from garbage and used tires, Chem Week. 2008;170(10).

[26]. Coskata Inc. webpage http://www.coskata.com/ (accessed November 2012)

[27]. V. Subramani, S.K. Gangwal, A review of recent literature to search for an efficient catalytic process for the conversion of syngas to ethanol, Energy and Fuels. 2008;22(2):814-39.

[28]. C. Reyes Valle, A.L. Villanueva Perales, P. Ollero, A. Gómez-Barea, Techno-economic assessment of biomass-to-ethanol by indirect fluidized bed gasification: impact of reforming technologies and comparison with entrained flow gasification. Unpublished results.

[29]. S.D. Phillips, Technoeconomic analysis of a lignocellulosic biomass indirect gasification process to make ethanol via mixed alcohols synthesis, Industrial and Engineering Chemistry Research. 2007;46(26):8887-97.

[30].Y. Zhu, M.A. Gerber, S.B. Jones, D.J. Stevens, Analysis of the Effects of Compositional and Configurational Assumptions on Product Costs for the Thermochemical Conversion of Lignocellulosic Biomass to Mixed Alcohols - FY 2007 Progress Report, Pacific Northwest National Laboratory, December 2008.

[31]. A. Dutta, S. Phillips, Thermochemical ethanol via direct gasification and mixed alcohol synthesis of lignocellulosic biomass, NREL/TP-510-45913, 2009. http://www.nrel.gov/docs/fy07osti/41168.pdf

[32]. S.D. Phillips, J. Tarud, M. Biddy, A. Dutta, Gasoline fromwood via integrated gasification, synthesis, and methanol-to-gasoline technologies. NREL/TP-5100-47594 National Renewable Energy Laboratory (NREL), Golden, CO, 2011.

[33]. J. He, W. Zhang, Techno-economic evaluation of thermo-chemical biomass-to-ethanol, Applied Energy. 2011;88(4):1224-32.

[34]. A. Dutta, M. Talmadge, J. Hensley, M. Worley, D. Dudgeon, D. Barton, et al., Process Design and Economics for Conversion of Lignocellulosic Biomass to Ethanol: Thermochemical Pathway by Indirect Gasification and Mixed Alcohol Synthesis, Golden (CO): National Renewable Energy Laboratory; 2011 May. Report No.: NREL/TP-5100-51400, Contract No.: DE-AC36-08G028308. Sponsored by the Department of Energy.

[35]. A. Dutta, M. Talmadge, J. Hensley, M. Worley, D. Dudgeon, D. Barton, et al., Techno-economics for conversion of lignocellulosic biomass to ethanol by indirect gasification and mixed alcohol synthesis, Environmental Progress and Sustainable Energy. 2012;31(2):182-90.

[36]. J.J. Spivey, A. Egbebi, Heterogeneous catalytic synthesis of ethanol from biomass-derived syngas, Chem Soc Rev. 2007;36(9):1514-28.

[37]. P. Haro, P. Ollero, A.L. Villanueva Perales, C. Reyes Valle, A Short Review on $2^{\text {nd }}$ Generation Processes to Produce Ethanol from Biomass, 20th European Biomass Conference and Exhibition. 18-22 June 2012. Milan (Italy).

[38]. V.F. Tret'yakov, Y.I. Makarfi, K.V. Tret'yakov, N.A. Frantsuzova, R.M. Talyshinskii, The catalytic conversion of bioethanol to hydrocarbon fuel: A review and study, Catalysis in Industry. 2010;2(4):402-20.

[39]. Y. Chen, Y. Wu, L. Tao, B. Dai, M. Yang, Z. Chen, et al., Dehydration reaction of bio-ethanol to ethylene over modified SAPO catalysts, Journal of Industrial and Engineering Chemistry. 2010;16(5):717-22.

[40]. C.B. Phillips, R. Datta, Production of ethylene from hydrous ethanol on H-ZSM-5 under mild conditions, Industrial and Engineering Chemistry Research. 1997;36(11):4466-75. 
[41]. I. Takahara, M. Saito, M. Inaba, K. Murata, Dehydration of ethanol into ethylene over solid acid catalysts, Catalysis Letters. 2005;105(3-4):249-52.

[42]. Y. Hu, N. Zhan, C. Dou, H. Huang, Y. Han, D. Yu, et al., Selective dehydration of bio-ethanol to ethylene catalyzed by lanthanum-phosphorous-modified HZSM-5: Influence of the fusel, Biotechnology Journal. 2010;5(11):1186-91.

[43]. Ethylene from Ethanol, Chematur's Brochure. http://www.chematur.se/sok/download/Ethylene_rev_0904.pdf (accessed February 2012)

[44]. E. Henrich, N. Dahmen, E. Dinjus, Cost estimate for biosynfuel production via biosyncrude gasification, Biofuels, Bioproducts and Biorefining 3 (2009) 28-41.

[45]. K. Raffelt, E. Henrich, A. Koegel, R. Stahl, J. Steinhardt, F. Weirich, The BTL2 process of biomass utilization entrained-flow gasification of pyrolyzed biomass slurries, Applied Biochemistry and Biotechnology 129 (2006) 153-164.

[46]. M. Wright, R. Brown, A. Boateng, Distributed processing of biomass to bio-oil for subsequent production of Fischer-Tropsch liquids, Biofuels, Bioproducts and Biorefining 2 (2008) 229-238.

[47]. F. Trippe, M. Fröhling, F. Schultmann, R. Stahl, E. Henrich, Techno-economic analysis of fast pyrolysis as a process step within biomass-to-liquid fuel production, Waste and Biomass Valorization 1 (2010) 415-430.

[48]. F. Trippe, M. Fröhling, F. Schultmann, R. Stahl, E. Henrich, Techno-economic assessment of gasification as a process step within biomass-to-liquid (BtL) fuel and chemicals production, Fuel Processing Technology 92 (2011) 2169-2184.

[49]. Aspen Physical Property System. Physical property methods. Aspen Technology; 2007.

[50]. R. Smith, Chemical Process Design and Integration, Wiley, Chichester, 2005.

[51]. M.S. Peters, K.D. Timmerhaus, R.E. West, Plant design and economics for chemical engineers, 5. ed., international ed. ed. Boston [u.a.]: McGraw-Hill; 2003.

[52]. E.D. Larson, J. Haiming, C.E. Fuat, Gasification-Based Fuels and Electricity Production from Biomass, without and with Carbon Capture and Storage, Princeton, NJ: Princeton Environmental Institute, Princeton University; 2005.

[53]. A. Chauvel, Manual of Process Economic Evaluation, Editions Technip, Paris, 2003.

[54]. European Commission, Inforeuro US Dollar, European Union, Brussels, 2011.

[55]. $\mathrm{VCl}$, Chemiewirtschaft in Zahlen, Verband der Chemischen Industrie e.V. (VCl), Frankfurt a.M., 2012.

[56]. F. Trippe, et al., Comprehensive techno-economic assessment of dimethyl ether (DME) synthesis and Fischer-Tropsch synthesis as alternative process steps within biomass-to-liquid production, Fuel Process Technology 106 (2013) 577-586.

[57]. D. Lumma, B. Kaufmann, R. Errington, Taylorville Energy Center - Basis of Estimate, Kiewit/Burns \& McDonnell Joint Venture (KBMD Partners), Kansas City, Mo., 2010.

[58]. Eurostat, Electricity - Industrial Consumers - Half-Yearly Prices (Germany), European Commission, Brussels, 2012.

[59]. S.B. Jones, Y. Zhu, Techno-economic analysis for the conversion of lignocellulosic biomass to gasoline via the methanol-to-gasoline (MTG) process. PNNL-18481 Pacific Northwest National Laboratory (PNNL), Richland, WA, 2009.

[60]. J.C. Meerman, E.S. Hamborg, T. van Keulen, A. Ramírez, W.C. Turkenburg, A.P.C. Faaij, Technoeconomic assessment of $\mathrm{CO}_{2}$ capture at steam methane reforming facilities using commercially available technology, International Journal of Greenhouse Gas Control. 2012;9:160-71.

[61]. H.S. Kheshgi, R.C. Prince, Sequestration of fermentation $\mathrm{CO}_{2}$ from ethanol production, Energy. 2005;30(10):1865-71.

[62]. P.D.R. Williams, D. Inman, A. Aden, G.A. Heath, Environmental and sustainability factors associated with next-generation biofuels in the U.S.: What do we really know?, Environmental Science and 
Technology. 2009;43(13):4763-75.

[63]. $\mathrm{CO}_{2}$ Capture and Storage: A Key Carbon Abatement Option, International Energy Agency (IEA). OECD Publishing, 2008.

[64]. Y. Xu, L. Isom, M.A. Hanna, Adding value to carbon dioxide from ethanol fermentations, Bioresour Technol. 2010;101(10):3311-9.

[65]. E.G. Lindfeldt, M.O. Westermark, Biofuel production with CCS as a strategy for creating a $\mathrm{CO}_{2^{-}}$ neutral road transport sector, Energy Procedia. 2009;1(1):4111-8. 